\title{
Polymorphic ribonucleoprotein folding as a basis for translational regulation
}

Tom Dendooven, Elisabeth Sonnleitner*, Udo Bläsi* and Ben F. Luisi

Department of Biochemistry, University of Cambridge, Tennis Court Road, Cambridge CB2 1GA, U.K.

*Department of Microbiology, Immunobiology and Genetics, Max Perutz Labs, University of Vienna, Vienna Biocenter (VBC), Dr. Bohrgasse 9/4, 1030 Vienna, Austria.

\section{Abstract}

The widely occurring bacterial RNA chaperone $\mathrm{Hfq}$ is a key factor in the post-transcriptional control of hundreds of genes in Pseudomonas aeruginosa. How this broadly acting protein can contribute to the regulation requirements of so many different genes remains puzzling. Here, we describe the structures of higher-order assemblies formed on control regions of different $P$. aeruginosa target mRNAs by $\mathrm{Hfq}$ and its partner protein $\mathrm{Crc}$. Our results show that these assemblies have mRNA-specific quaternary architectures resulting from the combination of multivalent protein-protein interfaces and recognition of patterns in the RNA sequence. The structural polymorphism of the ribonucleoprotein assemblies enables selective translational repression of many different target mRNAs. This system suggests how highly complex regulatory pathways can evolve and be rewired with a simple economy of proteinogenic components.

Keywords: co-transcriptional RNA folding, Crc, RNA chaperone $\mathrm{Hfq}$, metabolic regulation, translational regulation, ribonucleoprotein assembly 

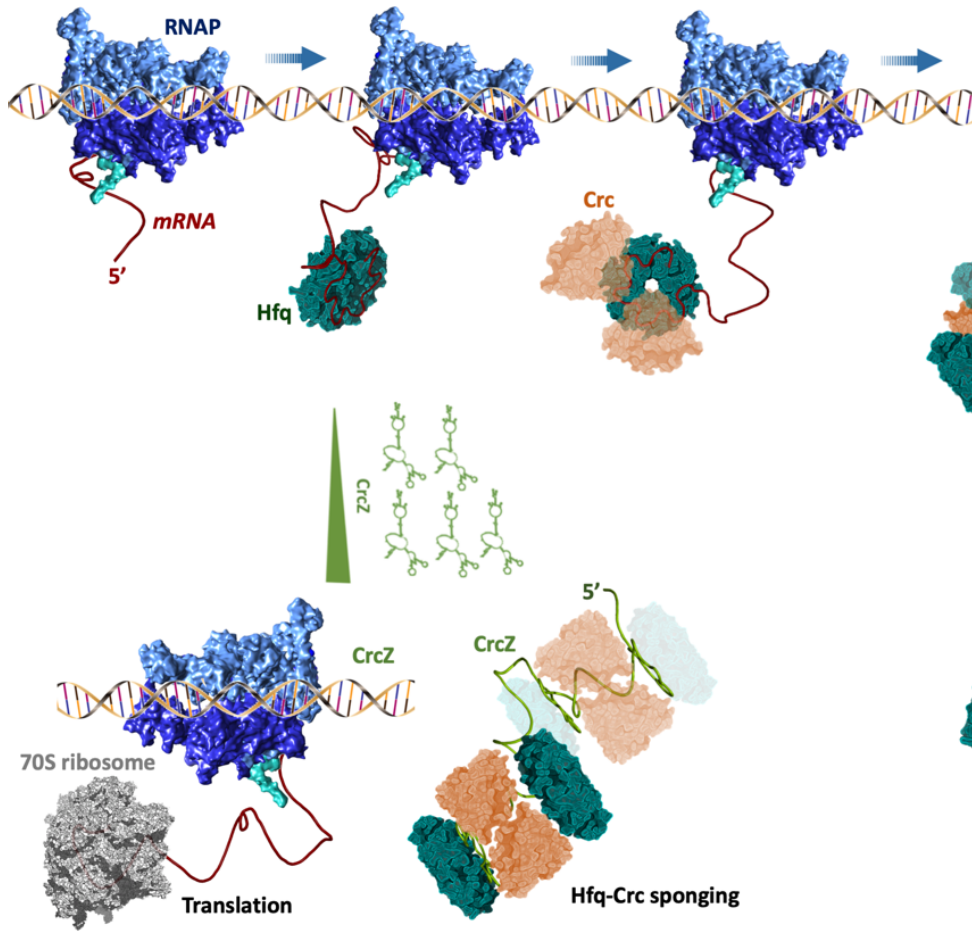

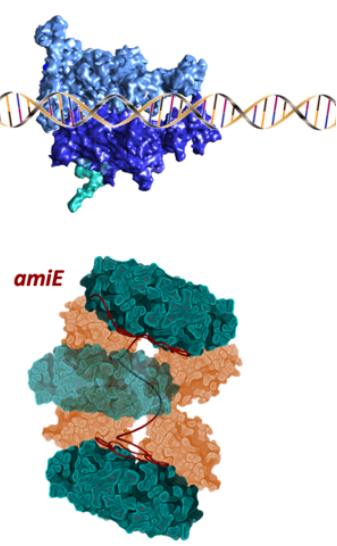

Polymorphic Translation repression
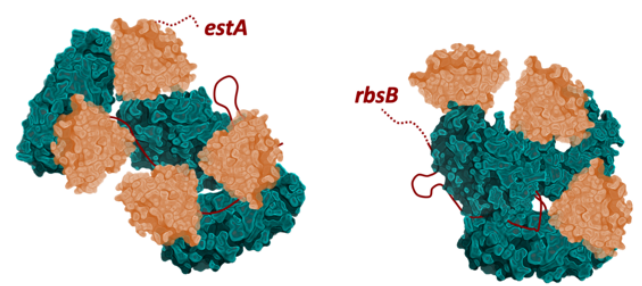

Graphical Abstract: The RNA chaperone Hfq, in conjunction with the co-repressor Crc, forms higher order assemblies on nascent mRNAs. These complexes impact on translation of hundreds of transcripts in the pathogen Pseudomonas aeruginosa. Assemblies with different quaternary structures result from the interactions of the proteins with sequence motifs and structural elements in different mRNA targets, as well as from a repertoire of protein-to-protein interfaces. In this way, the combination of RNA sequence and two proteins can generate the diversity required to regulate many genes. It is proposed that the multi-step assembly process is highly cooperative and most likely competes kinetically with translation initiation to silence the targeted transcripts.

49

50

51 
59

60
Two major post-transcriptional systems control gene expression in the pathogenic bacterium Pseudomonas aeruginosa. One system depends on the CsrA-like Rsm proteins, which act as translational repressors and engage GGA motifs in the Shine-Dalgarno sequence of target mRNAs that are often exposed in loops of stem-loop structures (Dubey et al., 2005; Schubert et al., 2007, Goodman et al., 2016; Holmqvist et al., 2016; Romero et al., 2018; Gebhardt et al., 2020). The other system depends on the RNA chaperone $\mathrm{Hfq}$, a member of the widely occurring Lsm/Sm protein family, which facilitates the actions of small regulatory RNAs (sRNAs; Pusic et al., 2021), and can act as a translational repressor of target mRNAs (Sonnleitner \& Bläsi, 2014; Sonnleitner et al., 2018; Kambara et al., 2018; Gebhardt et al., 2020; Malecka et al., 2021). Through these activities, Hfq contributes to the coordination of stress responses (Lu et al., 2016), metabolism (Sonnleitner \& Bläsi, 2014), quorum sensing (Sonnleitner et al., 2006; Yang et al., 2015), virulence (Sonnleitner et al., 2003), and affects complex processes such as biofilm formation and the antibiotic susceptibility (Fernàndez et al., 2016; Pusic et al., 2016, Zhang et al. 2017; Pusic et al., 2018; Sonnleitner et al., 2020).

Hfq-mediated translational repression forms the basis for a hierarchical control of carbon and nitrogen utilization by Pseudomonas spp., a mechanism referred to as carbon catabolite repression (CCR) (Rojo, 2010; Sonnleitner \& Bläsi, 2014). CCR ensures that alternative nutrients are not utilized until the preferred carbon source, succinate, is depleted. The regulation is exerted through translational repression of genes affecting the uptake and metabolism of non-preferred nutrients (Sonnleitner \& Bläsi, 2014). The best studied CCRregulated gene is amiE, which encodes the enzyme aliphatic amidase that generates organic acids from short-chain aliphatic amides, thereby enabling Pseudomonas to utilize acetamide as a source of both carbon and nitrogen. When preferred carbon sources such as succinate are abundant, translation of amiE mRNA is suppressed through sequestration of the ribosome binding site by $\mathrm{Hfq}$ and the catabolite control protein Crc (Figure 1), which is followed by mRNA degradation (Sonnleitner \& Bläsi, 2014). When the preferred carbon source is exhausted, CCR is alleviated by the regulatory sRNA CrcZ (Figure 1), which sequesters Hfa away from substrate mRNAs (Sonnleitner \& Bläsi, 2014). The CrcZ levels are controlled by the alternative sigma factor RpoN (Sonnleitner et al., 2009; Abdou et al., 2011; Valentini et al., 2014) and the two-component system CbrA/B, which may be activated in response to the cellular energy status (Valentini et al., 2014). 
A
Catabolite repression
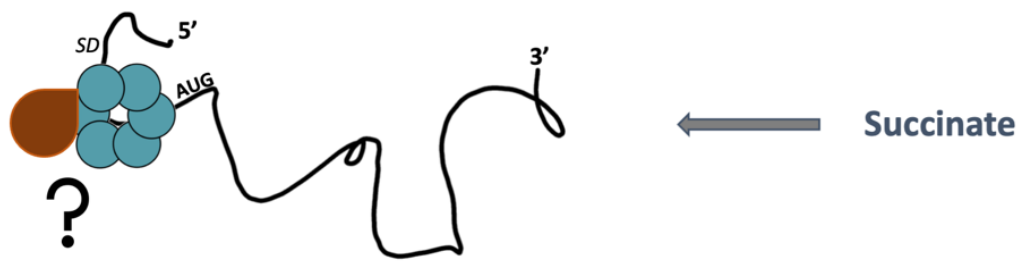

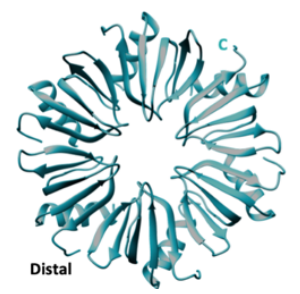

Proximal
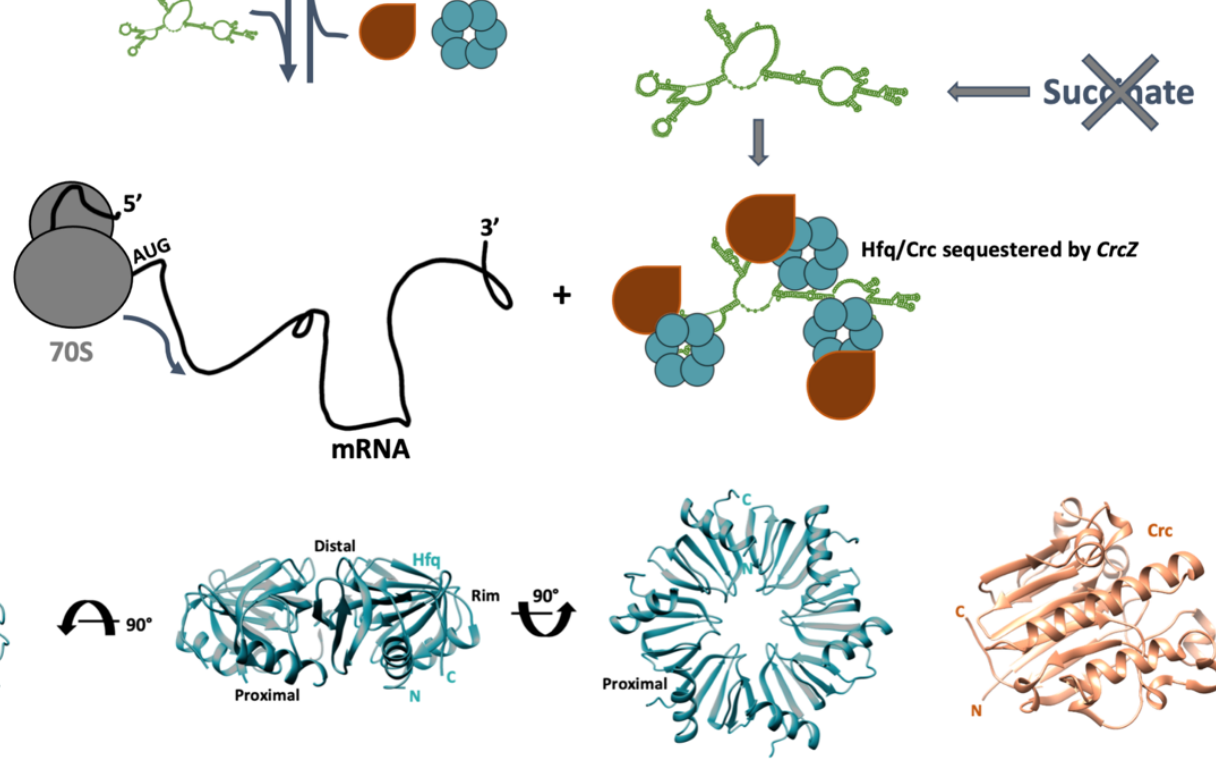

Translation

(n)

Figure 1: Catabolite repression in Pseudomonas spp. (A) During catabolite repression, e.g. when succinate levels are high (top), the Hfa hexamer and Crc cooperatively bind to A-rich sequences at the $5^{\prime}$-end of target mRNAs, and mask the ribosome binding site. When succinate levels are low (bottom), catabolite repression is alleviated by the regulatory RNA $\mathrm{CrcZ}$, which sequesters Hfq and/or Hfq/Crc complexes. (B) Crystal structures of Hfq hexamer, showing the distal, proximal and rim side (left three panels), and Crc (right panel).

Understanding the molecular basis of CCR has been advanced by structural insights into RNA recognition by Hfq. These have identified three different RNA binding surfaces on the Hfq hexamer: the proximal face, the distal face, and the circumferential rim (Figure 1B). The proximal face binds uridine tracts, which are enriched at the $3^{\prime}$ end of sRNAs, the distal face has sequence preference for ARN triplet motifs (where $A$ is an adenosine, $R$ a purine and $\mathrm{N}$ any base), and the rim has arginine-rich patches that can interact with UA rich motifs of RNAs (Santiago-Frangos \& Woodson, 2018). Cryo-EM structures of Hfq-Crc complexes on a short octadecameric segment derived from the $5^{\prime}$ upstream untranslated region (5'-UTR) of amiE mRNA (Supplementary Figure $1 \mathrm{~A}$; $a m i E_{6 A R N}$ ) revealed how the $\mathrm{Hfq}$ distal side presents the amiE ribosome binding site to $\mathrm{Crc}$ (Pei et al., 2019). In these structures two stacked $\mathrm{Hfq}$ hexamers each present one amiEGARN motif to four Crc protomers. The structures suggested that translation repression complexes are higher order assemblies where several $\mathrm{Hfq}$ hexamers and $\mathrm{Crc}$ molecules are engaged on the mRNA target. How the Pseudomonadspecific $\mathrm{Crc}$ molecule contributes to the repressive function of these CCR assemblies has been a long-standing question. Interestingly, $\mathrm{Crc}$ has no intrinsic RNA binding capacity and does not interact with $\mathrm{Hfq}$ in the absence of a RNA substrate (Milojevic et al., 2013; Sonnleitner et al., 2018). Thus, the ability of $\mathrm{Crc}$ to engage Hfq-mRNA intermediates arises through the cooperative effects of the interactions in the higher order assemblies. In line with this model, single-molecule fluorescence assays and molecular dynamics simulations showed that $\mathrm{Crc}$ 
118 interacts with transient, pre-organized Hfq/RNA complexes and shifts the equilibrium 119 towards assemblies with increased stability so that the effector complex blocks translation 120 more efficiently (Malecka et al., 2021; Krepl et al., 2021). Thus, the cooperation of Hfq with 121 Crc effectively stabilizes the repressive complex, excluding the $30 \mathrm{~S}$ ribosomal subunit more 122 effectively than $\mathrm{Hfq}$ alone.

Recent RNA-seq and proteomics approaches have revealed how CCR controls more than 100 mRNA targets that are co-regulated by $\mathrm{Hfq}$ and $\mathrm{Crc}$, many of which are involved in carbon metabolism and virulence (Kambara et al., 2018; Corona et al., 2018). However, the diverse regulatory functions of $\mathrm{Hfq} / \mathrm{Crc}$ present a puzzling issue: how can the same two effector molecules target so many different mRNA sequences with specificity and individually tuned response? To explore this question, we solved the cryo-EM structures of $\mathrm{Hfq} / \mathrm{CrC}$ translation repression complexes assembled on extended 5 '-end segments of the amiE, estA and $r b s B$ genes, encoding an amidase, an esterase and a putative ribose transporter (Winsor et al., 2016), respectively, and present in vivo observations supporting our models. These structures revealed how multiple ARN repeats in the RNA targets are engaged by $\mathrm{Hfq}$ and $\mathrm{CrC}$ to form higher order repressive complexes. Strikingly, these complexes are polymorphic in quaternary organization. The determinants for the organization are a combination of RNA secondary structure elements and the position and length of the ARN motifs in the translation initiation region (TIR) of these transcripts. Permissive Crc dimerization- and small, versatile $\mathrm{Hfq}-\mathrm{RNA}-\mathrm{Hfq}$ interfaces further stabilize the diverse repressive assemblies. The polymorphic character of these complexes enables $\mathrm{Hfq}$ and $\mathrm{Crc}$ to target many genes, while maintaining sequence specificity. These findings define a new paradigm for in vivo action of $\mathrm{Hfq}$ through cooperation with the Crc helper protein to form diverse RNA-driven effector assemblies that regulate expression of numerous target genes. 
Based on our earlier cryo-EM structures of a complex formed by $\mathrm{Hfq}$ and $\mathrm{Crc}$ on an 18-mer element from the 5'-UTR of the amiE transcript (Pei et al., 2019), we hypothesized that higher order assemblies may form on longer mRNA segments that contain multiple ARN motifs in the TIR. Here, we studied $\mathrm{Hfq} / \mathrm{Crc}$ assembly on mRNA fragments derived from the TIRs of the amiE, est $A$ and $r b s B$ genes, all of which were previously shown to be regulated by $\mathrm{Hfq}$ and $\mathrm{CrC}$ (Sonnleitner \& Bläsi, 2014; Kambara et al., 2018). As shown in Supplementary Figure $1 \mathrm{~A}$ and Supplementary Figure $4 \mathrm{~A}$, the amiE $E_{6 A R N}$ sequence present in the $5^{\prime}$ UTR of the amiE gene is followed by one cluster of 3 complete ARN motifs in the immediate coding region, the $a m i E_{X A R N}$ motif, and two ARN triplet motifs further downstream. These downstream ARN motifs have been implicated in $\mathrm{Hfq}$ binding in vivo by proximity crosslinking of $\mathrm{Hfq}$ and DNA in nascent transcripts followed by $\mathrm{Hfq}$-specific chromatin immunoprecipitation coupled with DNA sequencing (ChIP-seq) (Kambara et al., 2018). In contrast to amiE RNA, clusters of ARN motifs are predominantly found in the $5^{\prime}$-UTR of $r b s B$ and estA mRNA, rather than in the immediate $5^{\prime}$ coding region, which is in accord with the reported ChIP-seq data (Kambara et al., 2018). To verify that higher order assemblies form on different mRNA targets in vitro, electrophoretic mobility shift assays were performed with the mRNA fragments $a m i E_{105}$ (nts -45 to +60 ), $r b s B_{110}$ (nts -75 to +33 ) and $e s t A_{118}$ (nts -85 to +33 ) (Supplementary Figure $1 \mathrm{~B}$ ). For all three transcripts, a number of higher order species was observed to form gradually with increasing Hfq concentrations (Supplementary Figure 1B, lanes 1-5). In the presence of excess $\mathrm{Crc}$, formation of higher order species plateaued at around three $\mathrm{Hfq}$ hexamers per RNA target for all mRNA fragments tested (Supplementary Figure 1B; lanes 7-9). These observations supported the hypothesis that multiple Hfq hexamers can engage different ARNrich motifs in a mRNA target and form defined species in the presence of Crc.

\section{Sequential formation of higher-order Hfq-Crc assemblies from a core complex}

To characterize the details of the oligomeric state and quaternary structure, the Hfq-Crc complex formed on $\mathrm{amiE}_{105}$ was analyzed by cryo-EM. For the grid preparation a Hfq-titration series was performed like that used for the EMSAs shown in Supplementary Figure 1B. Figure $2 \mathrm{~A}$ shows a gallery of the key species observed in the titration series. Stable intermediates can be resolved on the grid, and these have been ordered in the gallery in a proposed assembly pathway. Although it is possible that the pathway for the formation of the higher order complexes may be heterogenous, based on the observed species we propose a pathway where in the first step, a $\mathrm{Hfq}-\mathrm{Crc}-\mathrm{Crc}$ core is formed, whereby the amiE $E_{6 A R N}$ region is bound by the $\mathrm{Hfq}$ distal side with two $\mathrm{Crc}$ molecules recognizing and engaging the $\mathrm{Hfq}$-RNA complex (Figure 2A, left, 2:1:1 Hfq:amiE $E_{105}: \mathrm{Crc}$ ). From this core, another $\mathrm{Hfq}$ and $\mathrm{Crc}$ can bind to form a higher order intermediate (Figure $2 \mathrm{~A}$, middle, 2:1:3 $\mathrm{Hfq}: a m i E_{105}: \mathrm{Crc}$ ), and in a final step, a third Hfq engages the intermediate assembly, together with a fourth Crc molecule (Figure 2A, right, 3:1:4 $\mathrm{Hfq}:$ ami $\left._{105}: \mathrm{Crc}\right)$. The structure of the 3:1:4 $\mathrm{Hfq}:$ ami $_{105}$ :Crc complex was solved at $3.6 \AA$ A resolution (GS-FSC, gold standard Fourier shell correlation (Supplementary Figure 2A, prevent translational initiation. 
bioRxiv preprint doi: https://doi.org/10.1101/2022.02.11.480102; this version posted February 12, 2022. The copyright holder for this

preprint (which was not certified by peer review) is the author/funder, who has granted bioRxiv a license to display the preprint in perpetuity. It is made available under aCC-BY 4.0 International license.

188

A

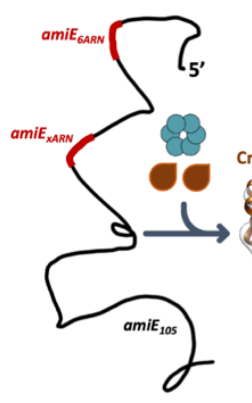
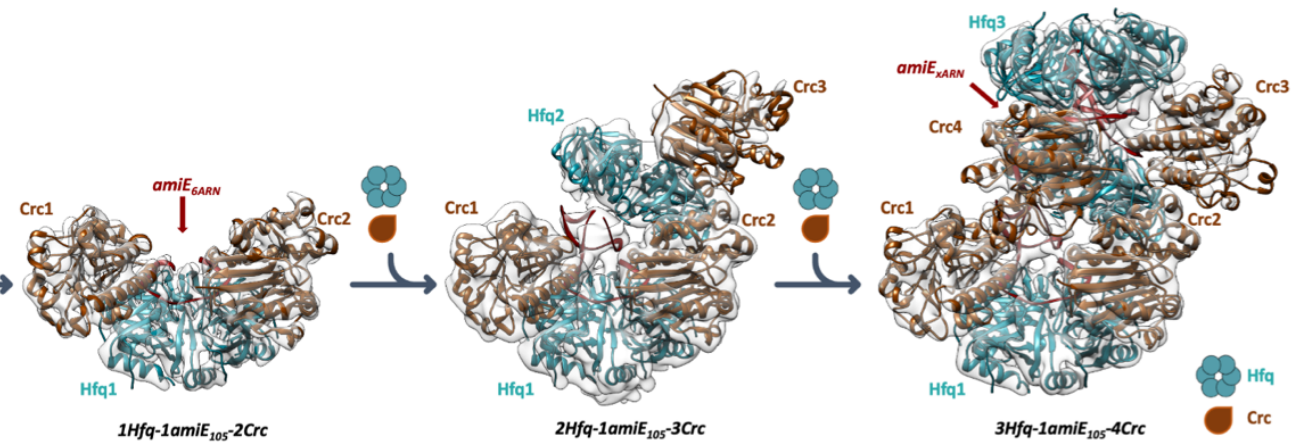

B
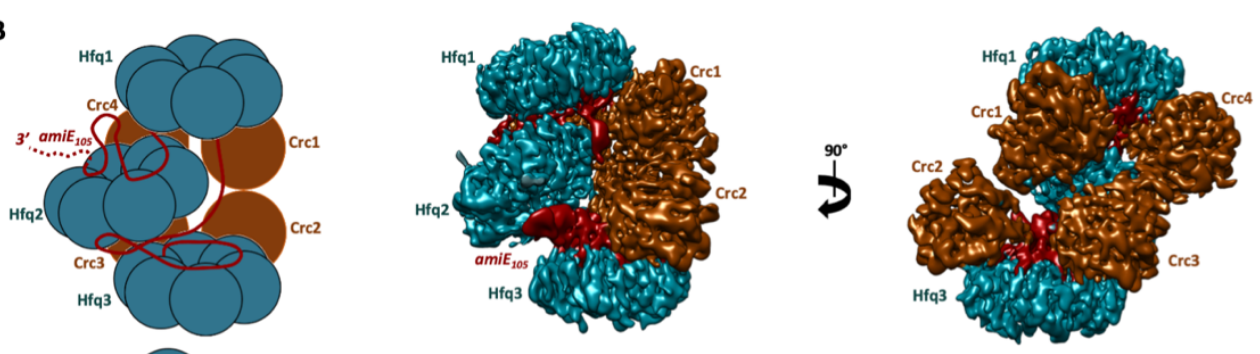

C
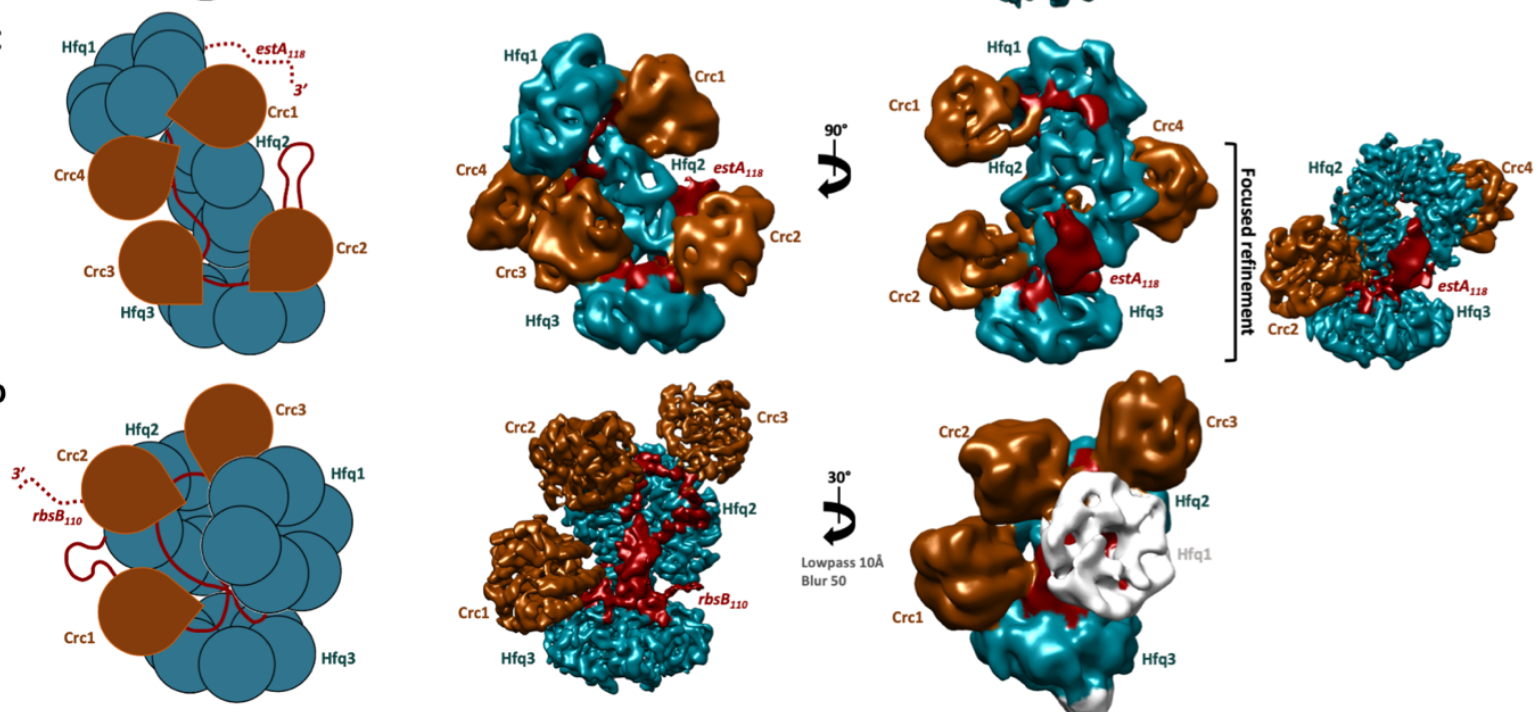

Figure 2: $\mathrm{Hfq}$-Crc translation repression assembly pathway, and complexes formed on amiE $\mathrm{E}_{105}$, est $\mathrm{A}_{118}$ and $\mathrm{rbs} \mathrm{B}_{110}$. (A) $A$ proposed cooperative assembly pathway for $\mathrm{Hfq}$-Crc assemblies on amiE ${ }_{105}$. The amiE $E_{6 A R N}$ region (Figure $1 \mathrm{~A}$ ) is bound by the $\mathrm{Hfq}$ distal side. Subsequently, two Crc molecules recognize and engage the Hfq-RNA complex (left). An additional Hfq and Crc can then bind to form a higher order intermediate (middle). In a final step, a third Hfa engages the intermediate assembly, together with a fourth Crc molecule (right). The final complex fully masks the amiE $E_{105} 5^{\prime}$-end and is proposed to inhibit translation initiation. (B) Schematic of the amiE $\mathrm{E}_{105}$ translation repression complex where two Hfa hexamers (Hfq1 \& 3) enclose four Crc molecules (Crc1-4) and a third Hfq hexamer (Hfq2). The amiE $\mathrm{F}_{105}$ fragment threads through the complex, engaged by all three $\mathrm{Hfq}$ hexamers and all four Crc molecules. (C) In the est $\mathrm{A}_{118}$ complex two Hfq hexamers (Hfq 1 \& 3)

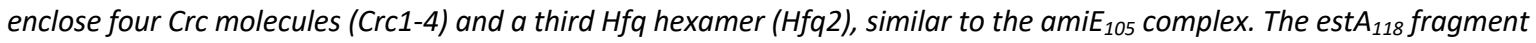
threads through the assembly and contacts all three Hfq hexamers and all four Crc molecules. Hfal and Crc1 are flexibly tethered to the translation repression complex and were excluded during local refinements (right panel) (see Supplementary Figure 3). Global Hfq-Crc-est $A_{118}$ maps were lowpass filtered to $9 \AA$ to aid visualisation (middle two maps). The locally refined map is shown at $4.1 \AA$ (right). (D) Three Hfq hexamers (Hfq1-3) present the rbsB $B_{110}$ mRNA to three Crc molecules (Crc1-3). The density for Hfq1 is diffuse, which may be explained by flexible association of Hfq to the translation repression complex (see Supplementary Figure 3). 
To further elucidate the architectural principles of $\mathrm{Hfq} / \mathrm{Crc}$ repressive complexes, we solved structures of $\mathrm{Hfq}-\mathrm{Crc}$ complexes formed on the TIRs of the est $A_{118}$ and $r b s B_{110}$ mRNA segments (Supplementary Figure 1A). Representative images and 2D class averages are shown in the Supplementary Figures $2 B$ and $C$, and $3 D$. The reconstructions were generated at $4.4 \AA$ and $3.8 \AA$ resolution, respectively (Figure $2 \mathrm{C}$ and D, Supplementary Figure 3D-I). Focused refinements resulted in a $4.1 \AA$ resolution reconstruction of a sub-assembly of the $\mathrm{Hfq}:$ est $_{118}$ :Crc complex (Figure $2 \mathrm{C}$; right inset, Supplementary Figure $3 \mathrm{E}$ ). In both complexes, the mRNA target sequences are bound by three Hfq hexamers, and three $\left(r b s B_{110}\right)$ or four $\left(\right.$ est $\left.A_{118}\right)$ Crc molecules (Figure 2C-D). Notably, we observed different quaternary structures for each mRNA target, amiE $E_{105}$, est $A_{118}$ and $r b s B_{110}$, demonstrating the assembly of polymorphic $\mathrm{Hfq}-\mathrm{Crc}$ RNPs, driven by the mRNA sequence (Figure 2B, C and D and Supplementary Figure 4). From these structures, recurring features can be observed that define architectural principles of $\mathrm{Hfq} / \mathrm{Crc}$ assembly during CCR.

In all three $\mathrm{Hfq} / \mathrm{Crc}$ complexes with $a m i E_{105}$, est $A_{118}$ and $r b s B_{110}$, the ARN-rich motifs in the mRNA target sequences are bound by $\mathrm{Hfq}$ as described in our recent study on the HfqCrc-amiE $E_{6 A R N}$ assembly (Pei et al., 2019), where the Hfq distal surface engages the ARN motifs as noted by Link et al. (2009). In this interaction the A- and R-site bases are bound in basic pockets on the $\mathrm{Hfq}$ distal side, while the $\mathrm{N}$-bases are exposed, as such presenting the RNA for interaction with $\mathrm{Crc}$ partner molecules. Interestingly, all three complexes constitute a modular assembly that consists of one (est $A_{118}$ and $\left.r b_{s} B_{110}\right)$ or two (amiE $E_{105}$ ) copies of the same $\mathrm{Hfq}-\mathrm{Crc}-\mathrm{Crc}$ core unit (Figure $3 \mathrm{~A}, \mathrm{~B}$ and $\mathrm{C}$ ), where a basic patch on the two Crc molecules engages mainly the phosphate backbone of the presented ARN motif (Figure $3 C$ and $D$ ). To test the importance of this basic patch in vivo, translational lacZ reporter genes were designed for each target mRNA. The translation repression of these reporter constructs was then assessed in the presence of different Crc mutant proteins. Indeed, substitution of basic residues at the interface ( $\mathrm{CrC}$ residues $\mathrm{R} 140 \mathrm{~A}$ and $\mathrm{R} 140 / 141 \mathrm{~A}, \mathrm{R} 138 / 139 \mathrm{~A}$ ) reduced translation repression to $\triangle C r c$ levels for all three reporter genes amiE+60::lacZ; , est $A+18::$ lac $Z$ and $r b s B+13:: / a c Z$ ) (Figure $3 \mathrm{H}$ ). These in vivo results corroborate the importance of the RNA interactions for translational repression of mRNA targets by $\mathrm{Crc}$. For the $\mathrm{Hfq}-\mathrm{ami}_{105}-\mathrm{Crc}$ assembly, the downstream amiE $E_{X A R N}$ motif in the proximal coding region (Supplementary Figure $1 \mathrm{~A}$ ) only partially occupies the $\mathrm{Hfq}$ distal side yet still recruits $2 \mathrm{Crc}$ molecules (Crc1 and 4) ( $\mathrm{Hfq} 1$ in Supplementary Figure $4 A$ and Figure $3 A$ and $B$, left panels). Similarly, incomplete ARN-rich motifs partially decorate the $\mathrm{Hfq}$ distal sides in the est $A_{118}$ and $r b s B_{110}$ complexes (Supplementary Figure $4 \mathrm{~B}$ and $\mathrm{C}$ ), recruiting one or two additional $\mathrm{Crc}$ molecules per $\mathrm{Hfq}$ hexamer to the assembly (Figure 3B). All Crc molecules bind to the presented ARN motifs via the basic patch described above. Together, the structures of the translation repression assemblies and the validation studies in vivo indicate the importance of the common RNA interactions by $\mathrm{Crc}$. 
A

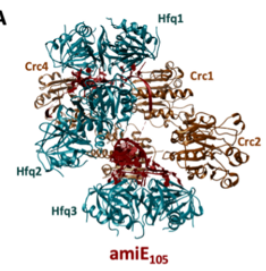

B

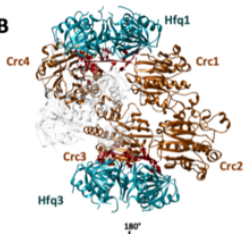

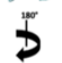

E
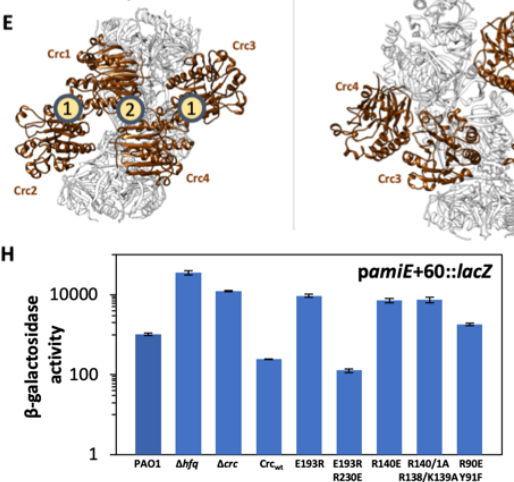
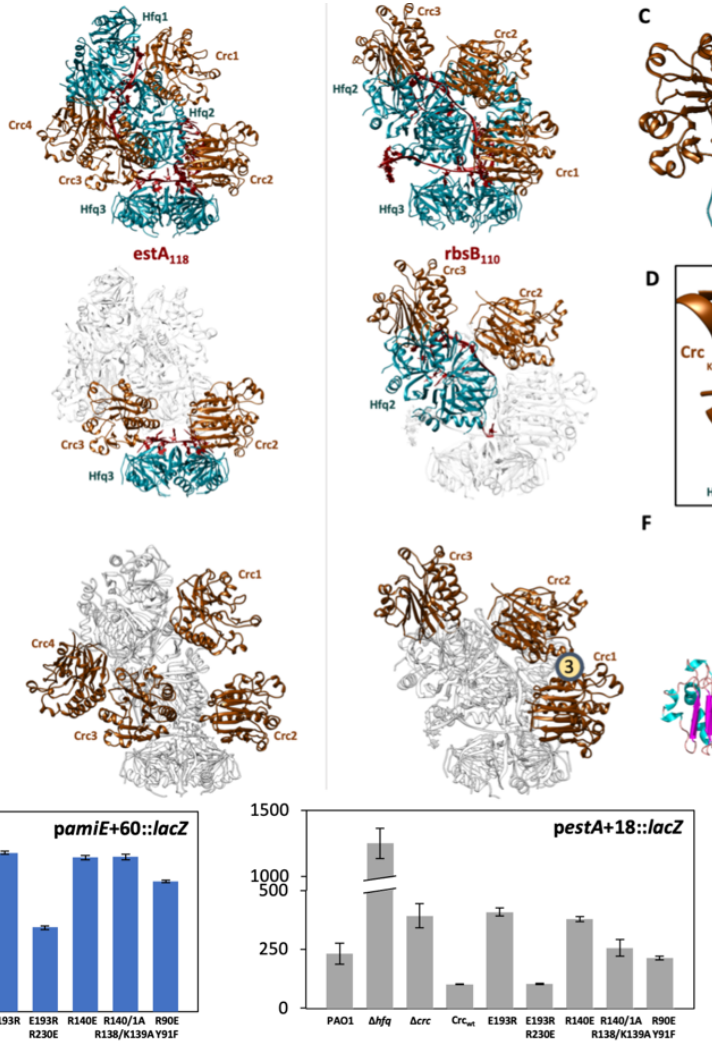

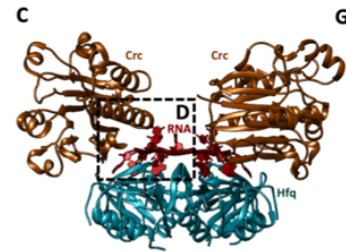

D
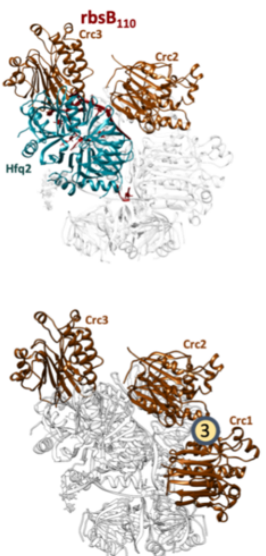

$\mathbf{F}$

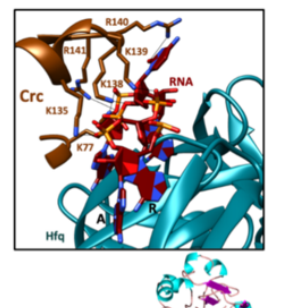

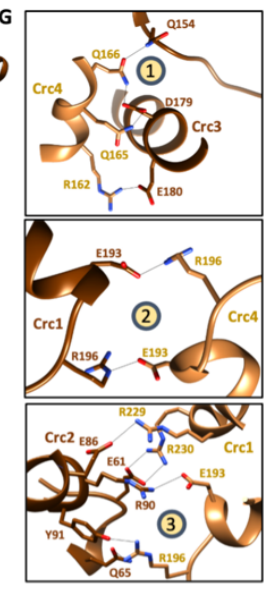
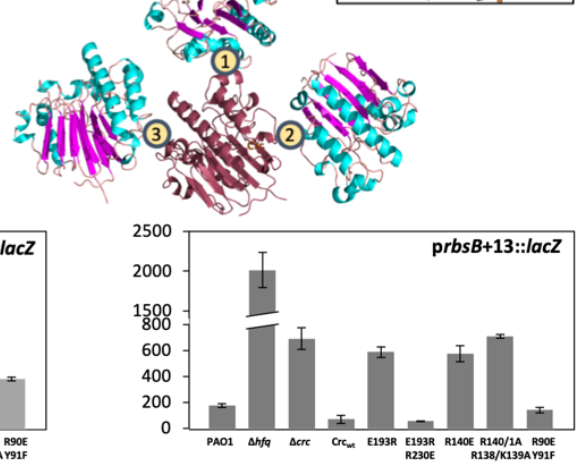

Figure 3: Conserved RNA binding by Crc and diverse protein-to-protein interfaces between Crc protomers in the Hfq-Crc assemblies on amiE as $_{105}$ est $A_{118}$ and $r b s B_{110}$. (A-C) All three assemblies are built from one or two Hfq-Crc-Crc core complexes, where Hfq presents - ARN-rich motifs to two Crc molecules. The full repressive assemblies formed on amiE ${ }_{105}$, est $A_{118}$ and $r b s B_{110}$ are depicted in panel $A$. In panel B, the same complexes are depicted, but only the Hfa-Crc-Crc core units are coloured. In panel C the common Hfq-Crc-Crc core complex is depicted. (D) A close-up of the Crc-RNA interactions in the core units. All Crc molecules in the repressive assemblies interact with the RNA via the same binding mode. A basic patch on the Crc surface, comprised of K77/K135/K138/K139/R140/R141, engages the phosphate backbone and a few N-site bases of the presented RNA on the Hfq distal side. (E-G) Crc forms homodimers in the ami $E_{105}$ and rbsB $B_{110}$ assemblies via diverse permissive dimer interfaces. Panel $E$ shows the full repressive assemblies formed on amiE $E_{105}$, est $A_{118}$ and rbs $B_{110}$ where only the Crc molecules are coloured. Three Crc dimer interfaces were observed in the ami $E_{105}$ and rbs $B_{110}$ complexes, annotated as 1, 2 and 3. Panel F shows the three Crc dimers observed, aligned and overlayed on a reference Crc molecule, with the interfaces annotated as in panel $E$. A close up of each dimer interface is given in panel $G$. (H) Translational regulation of amiE+60::lacZ, rbsB+13::lacZ and estA+18::lacZ reporter genes by Crc variants. $P$. aeruginosa strain $P A O 1 \triangle c r c$ harbouring either plasmids pamiE+60::lacZ (H; left panel), pestA+18::lacZ (H, middle panel)), prbs+13::lacZ (H, right panel) or plasmid pME4510 (vector control) together with pME4510 $\mathrm{crC}_{\text {Flag }}\left(\mathrm{CrC}_{w t}\right)$ or derivatives thereof encoding the respective mutant proteins was grown to an $O D_{600}$ of 2.0 in BSM medium supplemented with $40 \mathrm{mM}$ succinate and 40 mM acetamide (pamiE+60::lacZ) or $40 \mathrm{mM}$ succinate alone (pestA+18::lacZ and prbsB+13::lacZ). The $\beta$-galactosidase values conferred by the corresponding LacZ fusion proteins are indicated. The results represent data from two independent experiments and are shown as mean and range.

In the $a m i E_{105}$ and the $r b s B_{110}$ repressive assemblies Crc forms homodimers, and three different self-dimerization interfaces were observed (labeled as 1, 2 and 3 in Figure 3E, F, and $\mathrm{G})$, constituting a second recurring feature in the repressive assemblies. Since $\mathrm{Crc}$ is monomeric in solution at high $\mu \mathrm{M}$ concentrations, these dimerisation interfaces must require that the Crc molecules are organized in repressive assemblies. Substitution of Glu193 for Arg is predicted to disrupt the Crc interfaces 2 and 3 in the $a m i E_{105}$ and est $A_{118}$ assemblies due to electrostatic repulsion and impact translation repression (Figure 3G). Indeed, the E193R substitution in Crc reduced the translation repression of the amiE+60::/acZ and $r b s B+13:: / a c Z$ reporter genes to $\Delta \mathrm{Crc}$ levels (Figure $4 \mathrm{H}$ ). Compensation of the repulsive $\mathrm{Crc}$ interface by the 
R230E substitution in Crc in turn restored translation repression for the same amiE and $r b s B$ reporter genes (Figure $3 \mathrm{H}$ ). Although the Crc-Crc interfaces 2 and 3 are absent in the est $A_{118}$ complex, Crc residue E193 provides an alternative interaction with $\mathrm{Hfq} 2 \mathrm{~N} 28$ (chain V) and Hfq2 R19 (chain V) that is anticipated to be weakened by the E193R substitution, which might account for the observed weakened repression effect for the estA+18::/acZ reporter gene as well (Figure 3H). The substitution R230E in Crc can form interactions with Hfq2 N28 and R19 (chain $\mathrm{V}$ ), and can restore the $\mathrm{Hfq} / \mathrm{Crc}$ interface to compensate for the E193R substitution in the est $A_{118}$ complex. The hydrogen bonding interactions of R90 and Y91 in interface 3 of the $r b s B_{110}$ complex were tested with the double mutant R90E and $Y 91 \mathrm{~F}$, and found to have roughly a 2-fold effect on translational repression (Figure $3 \mathrm{H}$ ). Interface 3 does not occur in either the $a m i E_{105}$ or est $A_{118}$ complexes, where instead R90 and Y91 of Crc interact with the $\mathrm{C}$-terminal tail of a $\mathrm{Hfq}$ protomer. The double mutation R90E and Y91F de-repressed translation of the amiE and estA reporter genes roughly 7-fold and 2-fold, respectively. In summary, these results show that the Crc interaction surfaces can be directed to either form self-complementary contacts that support $\mathrm{Crc}-\mathrm{Crc}$ interactions or to contact $\mathrm{Hfq}$, both of which stabilize the polymorphic higher order repressive assemblies.

A third salient feature of the complexes is how the RNA is shared between adjacent $\mathrm{Hfq}$ molecules, where some $\mathrm{Hfq}$ distal sides present ARN motifs to the distal face or the rim of a neighbouring $\mathrm{Hfq}$ hexamer, rather than to $\mathrm{Crc}$ partner molecules. In the $\mathrm{Hfq}-\mathrm{amim}_{105}-\mathrm{CrC}$ assembly, the second amiE $E_{X A R N}$ motif in the amiE coding region is partially shared between the distal faces of $\mathrm{Hfq} 1$ and $\mathrm{Hfq} 2$, with nucleobases occupying alternating R-site pockets on both distal sides (Figure $4 A$ and $B$, Supplementary Figure $4 A$ ). This sharing of amiE $E_{X A R N}$ in the amiE coding region between $\mathrm{Hfq}$ molecules drives higher-order assembly formation and efficiently masks the ribosome binding site, rationalizing the observation that the downstream ARN cluster enhances translational repression of amiE in vivo (Supplementary Figure $1 \mathrm{C}$ and $\mathrm{D}$ ). In the $\mathrm{Hfq}-\mathrm{est}_{118}$ - $\mathrm{Crc}$ complex, $\mathrm{Hfq} 3$ presents the first longer $5^{\prime}$ ARN motif (Supplementary Figure 4B, 12-mer, four ARN triplet repeats) to the Hfq2 rim side (Figure 4F). The Hfq2 rim-side residues Arg19 and Arg66 form hydrogen bonds with the exposed N-site bases C-28 and U-25 of est $A_{118}$ (counting backward from the AUG start codon, with A annotated as nucleotide 1). Indeed, disruption of the ARN pattern of this $\mathrm{Hfq} 3$ binding site in the estA sequence resulted in a decrease in translation repression of the corresponding reporter gene by an order of magnitude in vivo (Figure $4 \mathrm{~J}, \mathrm{Hfq} 3_{\mathrm{mut}}$ ). Such disruption would also abrogate binding of estA by the $\mathrm{Hfq} 3$ distal side. A similar yet more extensive $\mathrm{Hfq}$-to-Hfq presentation of the RNA target is found in the Hfq- $r b s B_{110}-\mathrm{Crc}$ assembly, where a short RNRNmotif in the $r b s B_{110}$ coding region is presented by the $\mathrm{Hfq} 3$ distal side to the $\mathrm{Hfq} 2 \mathrm{rim} / \mathrm{proximal}$ side (Figure 4I). In particular, Hfq2 residues Arg16, Lys17 and Arg19 form hydrogen bonds with the phosphate backbone and the $C 6$ nucleobase of $r b s B_{110}$ (counting from the AUG start codon, with $A$ annotated as nucleotide 1 ). From these observations, it is apparent that completion of higher-order assembly enhances translational repression, and that RNAmediated $\mathrm{Hfq}-\mathrm{Hfq}$ oligomerization drives this process. 
bioRxiv preprint doi: https://doi.org/10.1101/2022.02.11.480102; this version posted February 12, 2022. The copyright holder for this preprint (which was not certified by peer review) is the author/funder, who has granted bioRxiv a license to display the preprint in perpetuity. It is made available under aCC-BY 4.0 International license.

A
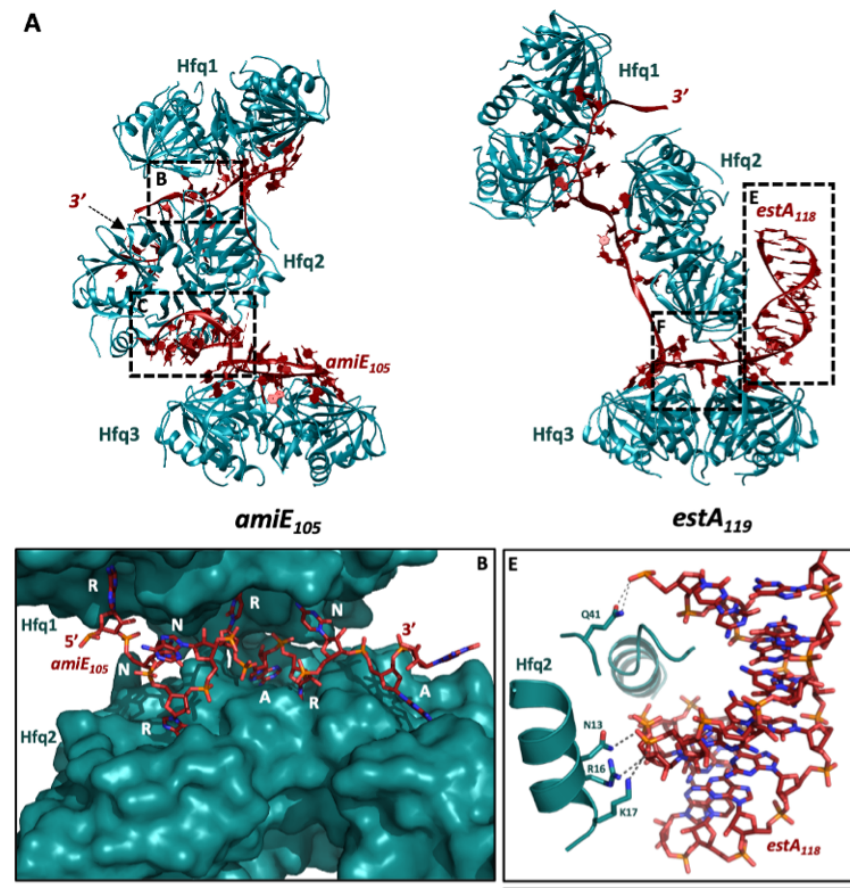

estA 119
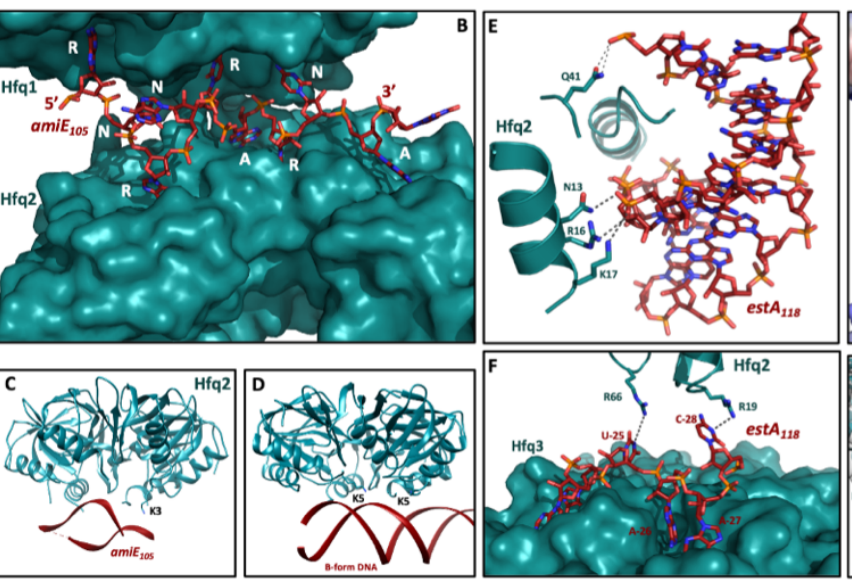

J estA+18

$\Delta$ hairpin1
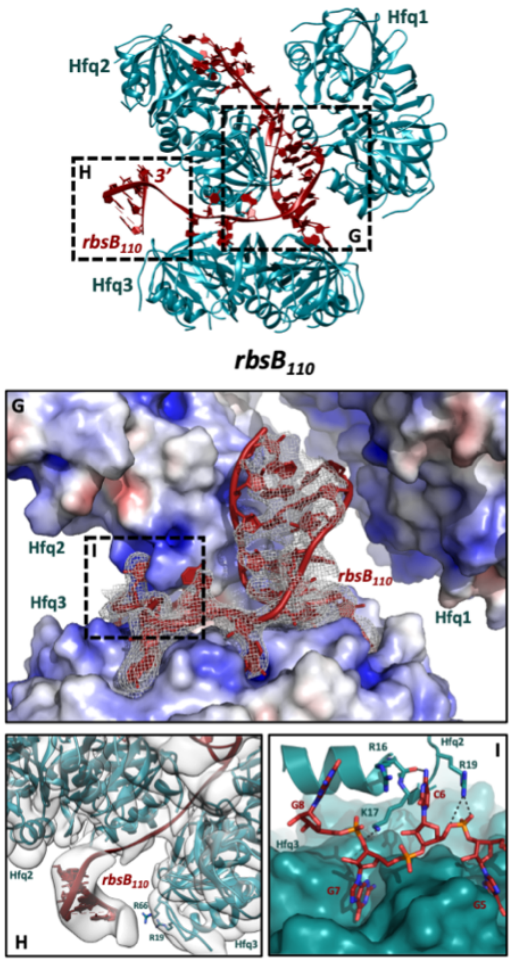

$r b s B_{110}$

TAAAAACAAATCA

Hfq3
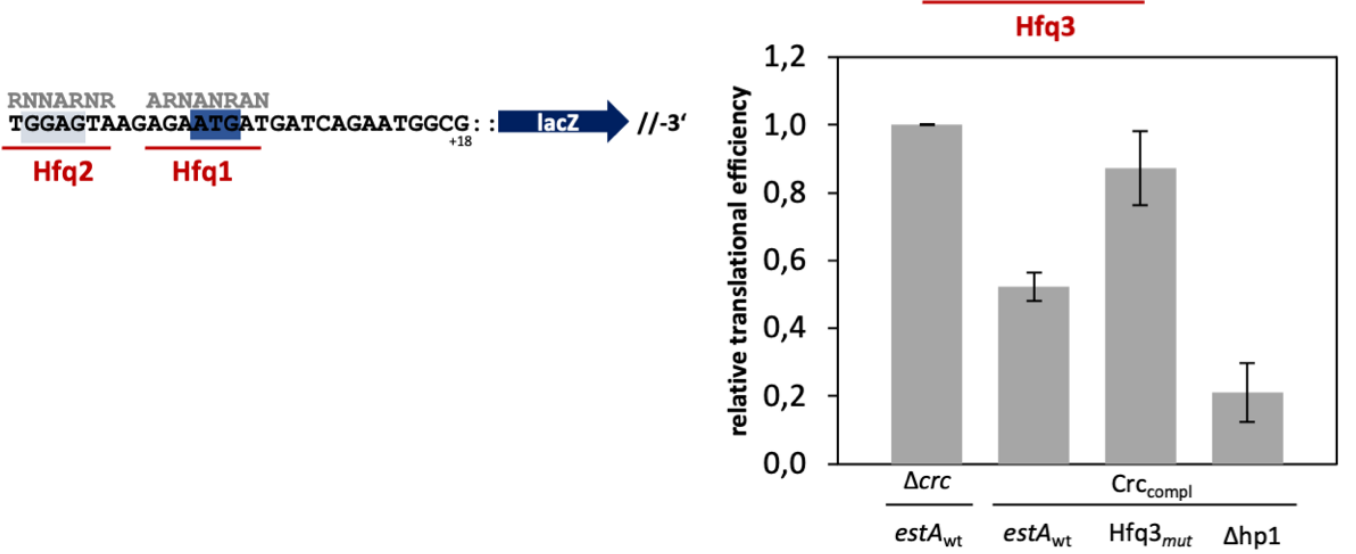

Figure 4: RNA sequence motifs and secondary structure elements drive oligomerization of the translation repression complexes. (A) $\mathrm{Hfq}$-RNA components of the repressive complexes formed on amiE $E_{105}$, est $A_{118}$ and rbs $B_{110}$ RNAs, shown without Crc for clarity. (B) Close-up of the second ARN -rich motif of amiE ${ }_{105}$, which is shared between the Hfq1 and Hfq2 distal sides. The R-site bases in the ARN -repeats occupy alternating R-site pockets on the two Hfa distal sides, enabling higher order assembly formation. (C) Close-up of a hairpin structure in amiE ${ }_{105}$, which is coordinated by the Hfa2 proximal side (see also supplementary Figure 3A, hairpin 1). Lys3 on the proximal helix of a Hfa 2 protomer is likely to form a polar contact with the RNA backbone in the duplex. (D) Crystal structure of E. coli Hfq bound to B-form DNA (Orans et al., 2020), where the DNA duplex binds the proximal face of the Hfq hexamer, analogous to the amiE ${ }_{105}$ hairpin in (C). (E) Close-up of a hairpin structure in est $A_{105}$, which is coordinated by the $\mathrm{Hfq} 2$ proximal side (see also Supplementary Figure 3B, hairpin1). Asn 13, Arg16 and Lys17 on the Hfq proximal helix coordinate the RNA backbone, as well as GIn41 on a proximal loop. (F) The ARN motif is bound to the Hfq3 distal side in the est $A_{119}$ assembly is shared with the Hfq2 rim side. In particular, Arg19 and Arg66 form hydrogen bonds with the C-28 and U-25 bases, respectively. (G) A duplex-like RNA fold is coordinated by basic patches on the $\mathrm{Hfq} 2$ and $\mathrm{Hfq} 3$ distal and proximal surfaces, respectively, in the rbs $\mathrm{B}_{110}$ repressive complex. $(\mathrm{H})$ At low threshold, density for a RNA duplex at the $\mathrm{rbs}_{110} 3^{3}$-end is apparent (see also Supplementary Figure 3C hairpin1), and is coordinated by the Hfq2 proximal side. The Hfq3 rim side can make putative hydrogen bonds with the hairpin backbone via 
Arg66 and Arg19. (I) As in (B) and (F), a short ARN motif in the rbsB $B_{110}$ sequence is shared between the Hfq3 distal side and the Hfq2 rim/proximal side. In particular, Hfq2 Arg16, Lys17 and Arg19 form contacts with the presented RNA backbone and bases in rbsB $B_{110}$. In all three complexes these Hfq-RNA-Hfq contacts drive higher order assembly formation. (J) Translational regulation of the estA+18::lacZ reporter gene and mutants thereof by $H f q$ and $\mathrm{Crc}$. The mRNA sequence of the 5 'UTR and the proximal coding region of estA+18::IacZ. ARN motifs bound to Hfa distal sides are annotated. The Shine Dalgarno sequence is highlighted in green and the AUG start codon is highlighted in blue. Mutations in the RNA sequence are indicated in green. Loss of the Hfq3 (Hfq3mut) binding element diminishes the repressive effects on estA mRNA significantly, whereas removal of the hairpin structure ( $\triangle \mathrm{hp} 1)$ results in a slight increase in translation repression. The $B-$ galactosidase activities were normalized to the respective mRNA levels (= relative translational efficiency) to account for intrinsic changes in mRNA stabilities eventually arising from the mutations introduced into the estA segment.

Finally, in all three complexes RNA duplex elements interact with the $\mathrm{Hfq}$ proximal sides in a sequence independent manner (Figure 4A, C, E, G and H, Supplementary Figure 4). Although the local resolutions were not sufficient to resolve side chains, it is apparent that these interactions are between basic and polar residues in the proximal $\mathrm{Hfq} \alpha$-helix and the phosphate backbone of the RNA duplex structures (Figure $4 \mathrm{C}$ and $\mathrm{E}$ ). In particular, the $\mathrm{Hfq}$ residues Lys3, Asn13, Arg16 and Lys17 are likely candidates for such interactions (Figure 4C and $\mathrm{E}$ ). This mode of RNA secondary structure recognition by $\mathrm{Hfq}$ is in line with findings of a recent crystallographic study by Orans et al. (2020), where $E$. coli $\mathrm{Hfq}$ was observed to interact with the phosphate backbone of B-form DNA (Figure 4D). It is unclear what role is played by this common mode of RNA duplex-binding by $\mathrm{Hfq}$ in the repressive assemblies. For est $A_{118}$, for example, removing the hairpin structure from the RNA construct resulted in a significantly stronger translation repression of the est $A+18::$ lac $Z$ reporter gene in vivo. Thus, the structural elements might confer either stabilizing or destabilizing contributions, depending on context.

In summary, the models of the repressive complexes formed on the amiE $E_{105}$, est $A_{118}$ and $r b s B_{110}$ transcripts and the in vivo reporter gene assays support a model in which the sharing of the target RNA between $\mathrm{Hfq} / \mathrm{Crc}$ molecules drives formation of higher order assemblies that fully mask the ribosome binding sites. Ultimately the RNA sequence determines the quaternary structure of such translation repression complex, through blocks of ARN-repeats that can have different spacing and local imperfections (Supplementary Figure 4), and through secondary structure elements. The polymorphic character of the assembly in turn is accommodated by the hexameric character of $\mathrm{Hfq}$, presenting a mosaic of basic patches on its surface, and consolidating interactions mediated through the permissive dimerization of organized $\mathrm{Crc}$ molecules. The different possible translation-repression assemblies, however, are all likely to fold following the recurring architectural principles described above.

\section{Discussion}

In $P$. aeruginosa carbon catabolite repression (CCR) controls not only carbon metabolism but also other complex behaviour including infection, virulence, biofilm formation, and quorum sensing. We have shown in this study that a key component of CCR, namely the RNA chaperone $\mathrm{Hfq}$, can form higher order assemblies on target mRNAs in conjunction with the protein $\mathrm{Crc}$, and that such assemblies repress translation. Our cryoEM analyses reveal distinct quaternary organisations of the assemblies on the regulatory regions of the amiE, est $A$ and rbsB mRNAs, which encode metabolic and virulence machinery and are known to be downregulated during carbon catabolite repression (Sonnleitner \& Bläsi, 2014; Kambara et al., 2018). 
The complexes are characterised by a common core sub-assembly, comprised of one $\mathrm{Hfq}$ hexamer which presents an ARN-rich motif to two Crc molecules (Figure $3 \mathrm{C}$ ). Based on the cryo-EM structures, we have elaborated rules that encode the architectural principles of translation repression assemblies. These are based on four recurring features of the complexes: i) the distal face of Hfq hexamer engages ARN-rich repeats, and is the sequence specificity determining factor. Crc can then interact with these elements via a distinct basic patch on its surface; ii) the proximal side of $\mathrm{Hfq}$ binds secondary structure elements in the RNA targets; iii) higher-order folding is driven by sharing of RNA segments between $\mathrm{Hfq}$ protomers and is enabled by the hexameric ring organisation of $\mathrm{Hfq}$, in which protomers rich in RNA binding patches provide repetitive RNA-interaction sites. Notably, the Hfq-Hfq and $\mathrm{Hfq}-\mathrm{Crc}$ interfaces formed in the translation repression complexes are almost exclusively through mutual interactions with the RNA substrate. In other words, $\mathrm{Hfq}$ and $\mathrm{Crc}$ need to bind to a polymer (RNA) for higher order assemblies to form. Polymer-bound proteins have a higher propensity to interact with each other, as part of the entropy is already lost, enabling small surfaces to contribute. iv) Some of these small surfaces are formed between neighbouring $\mathrm{Crc}$ molecules in the complex. These $\mathrm{Crc}$ dimerization interfaces support the distinct quaternary structures, and its surfaces can switch between self-complementary association or interaction with RNA/Hfq. From these principles, a diversity of quaternary structures can be supported that can regulate numerous genes in $P$. aeruginosa, with minimal proteinogenic components required.

$\mathrm{Hfq}$ is highly pleiotropic and involved in many riboregulatory processes. The envisaged multi-faceted control of CCR and processes linked to it entails a hidden cost of apparently requiring high numbers of $\mathrm{Hfq}$ and $\mathrm{Crc}$ in the cell, and the question arises if levels of the chaperone available are sufficient to meet the demands of forming higher order assemblies. Given that each mRNA leads to 100-1000 translated metabolic proteins on average, translational repression is only energetically beneficial for the cell if it is effective (Lynch \& Marinov, 2015). Hfq levels in $P$. aeruginosa have been calculated at $\sim 2200$ hexamers per cell during stationary phase, and nearly equimolar Crc levels per cell $(\sim 2300)$ were measured (Sonnleitner \& Bläsi, 2014; Sonnleitner et al., 2018). One scenario is that the pool is highly dynamic, and that $\mathrm{Hfq} / \mathrm{Crc}$ become available through rapid turnover of transcripts to which they are bound. Indeed, transcripts are poised for degradation after translational repression (Sonnleitner \& Bläsi, 2014), most likely releasing Hfq and Crc molecules that were sequestered in the repressive assembly. Secondly, genes encoding degradative proteins involved in metabolic pathways are generally only transcribed if the respective carbon source is available. This means that only a limited number of genes need to be translationally repressed in a given nutrient environment, i.e. the genes involved in metabolism of available yet non-favourable carbon sources. Lastly, it is possible that repressive responses might be graded through partial assemblies. Thus, sub-assemblies such as the $\mathrm{Hfq}-\mathrm{Crc}-\mathrm{Crc}$ core unit, might yield meaningful translation repression even when $\mathrm{Hfq} / \mathrm{Crc}$ levels are insufficient to drive higher order ribonucleoprotein folding. For instance, our in vivo studies indicate that the downstream amiE $E_{X A R N}$-motif of amiE present in the coding region ensures a more complete repression, but absence of this secondary motif still results in significant translation repression (Supplementary Figure 1D).

The biological impact of these assemblies might depend on windows of opportunity arising during the synthesis of the transcript. Sequential assembly of the Hfq-Crc complexes 
432

433

434

435

436

437

438

439

440

441

442

443

444

445

446

447

448

449

450

451

452

453

454

455

456

457

458

459

460

461

462

463

464

465

466

467

468

469

470

471

472

473

474

475

476

477

is envisaged to occur on nascent transcripts as they emerge from the RNA polymerase, potentially coupled with RNA folding in analogy with other systems (Kambara et al., 2018; Yu et al. 2021). Co-transcriptional folding of the RNA, for instance the formation of stem-loop structures that influence the quaternary architectures, could affect the rates of assembly and stabilities of the complexes. Single molecule studies have shown that target RNA secondary structure presents a kinetic energy barrier that determines whether target recognition occurs before stable pairing to sRNA (Malecka and Woodson, 2021). Extending this principle, we envisage that critical kinetic steps also occur in the assembly of $\mathrm{Hfq}-\mathrm{Crc}$ complexes on nascent transcripts. Indeed, removing the prominent hairpin structure that is recognised by the central $\mathrm{Hfq}$ in the est $A_{118}$ repressive complex (Figure $4 \mathrm{~A}$ and $\mathrm{E}, \mathrm{Hfq} 2$ ) promotes translational repression in vivo, suggesting a somewhat antagonistic role for such hairpin structures in the assembly pathway. Another indication that assembly of repressive complexes might be coupled to the transcription machinery is the observation that the $3^{\prime}$-end of transcripts that are repressed during CCR are diminished up to 10-fold in RNA sequencing analyses (Sonnleitner et al., 2018). One mechanism that could explain this observation is the recruitment of transcription termination factors during formation of the $\mathrm{Hfq} / \mathrm{Crc}$ complexes, coupling translation-repression of a transcript to termination of its transcription. This hypothesis awaits validation.

The RIL-seq results described by Kambara et al. (2018) and our on-grid Hfq-Crc-amiE assembly pathway (Figure 2A) point towards a stepwise assembly scenario, where protein binding occurs as soon as the ARN motifs are synthesized during transcription. However, given the high affinity of $\mathrm{Hfq}$ for RNA and the architectural principles described above, it is plausible that dynamic sampling of the RNA sequence and secondary structure elements by $\mathrm{Hfq}$ and/or $\mathrm{Crc}$, and synergistic recruitment of multiple copies of these, forms the basis for RNP assembly. As such, co-transcriptional Hfq-Crc assembly on an RNA target might bear analogy to the synergistic co-transcriptional assembly of ribosomes on rRNA (Rodgers \& Woodson 2019). If so, stepwise $\mathrm{Hfq}-\mathrm{Crc}$ assembly is not sequential, but rather depends on the contextual state of the RNA binding sites and the presence of other copies of $\mathrm{Hfq} / \mathrm{Crc}$ proteins. The difference here is that $\mathrm{Hfq} / \mathrm{Crq}$ assembly is tuned temporally and the resulting translation repression complexes are transient in nature, subject to kinetic competition, as distinct from folding equilibrium complexes such as ribosomes and spliceosome components (Herzel et al., 2017, Rodgers \& Woodson 2019).

The response to environmental changes and stress, and the re-routing of metabolic pathways demands systems of hierarchical control that form highly inter-connected networks. Such an intricate system is a demanding process for the cell, would require many specificity factors, i.e. protein components, to function properly. Here, we observe that specificity can be achieved with only two multifaceted protein factors and patterns in the RNA sequence. The modular nature of the protein factors and their mode of RNA interaction enables different quaternary organisations to result, i.e. less stringent folding-requirements for assembly. The regulatory outcome then becomes dependent on competitive kinetics of $\mathrm{Hfq}-\mathrm{Crc}$ assembly versus translational initiation, i.e. binding of the $30 \mathrm{~S}$ small ribosomal subunit to the mRNA RBS. Such an economic design also permits rapid modifications in network organization in the course of evolution through changes in the patterns of target RNA elements. As such, polymorphism of folded ribonucleoprotein complexes allows for a 
bioRxiv preprint doi: https://doi.org/10.1101/2022.02.11.480102; this version posted February $12,2022$. The copyright holder for this

preprint (which was not certified by peer review) is the author/funder, who has granted bioRxiv a license to display the preprint in perpetuity. It is made available under aCC-BY 4.0 International license.

478 simple, highly modular regulon that underpins the noted behavioural complexity of $P$.

479 aeruginosa. 
bioRxiv preprint doi: https://doi.org/10.1101/2022.02.11.480102; this version posted February 12, 2022. The copyright holder for this preprint (which was not certified by peer review) is the author/funder, who has granted bioRxiv a license to display the preprint in perpetuity. It is made available under aCC-BY 4.0 International license.

A

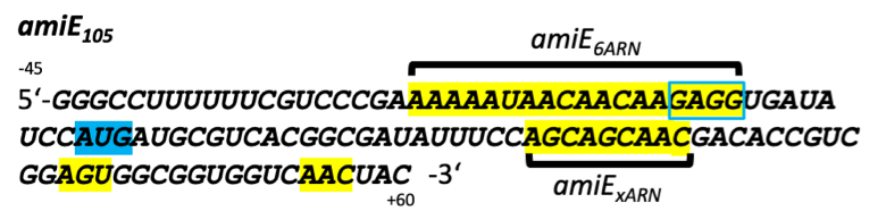

est $A_{118}$

$-85$

5'-GGCUGAGGAGGCUUUACGACGGGCCCCGGGGCGCAUGCCGAC GACGCGGCGGCCCGACAAUAAAAACAAAUCAUGGAGUAAGAGAAUG AUGAUCAGAAUGGCGCUCAAGCCACUGGUAGCG $-3^{\prime}$
C

amiE+3

$-242-45$

5'-//GGGCTTTTTTCGTCCCGAAAAAATAACAACAAGAGG

TGATATCCATG : : lacz $/ / / 3^{\prime}$

amiE+60

$-242-45$

5'-//GGGCCTTTTTTCGTCCCGAAAAAATAACAACAAGAGG TGATATCCATGCGTCACGGCGATATTTCCAGCAGCAACGA CACCGTCGGAGTGGCGGTGGTCAACTAC: : lacz $/ / 3^{\prime}$

D 5'-ggAACGCAAACGUUUGCGUCUGGAUAAUCUCCUGGAAAAGCCUC AAUACAACGAUAAGAAAAGCUGGAGGAUACACCAUGAAGCGGGUC GCUUCCCGGCGCCUGUUGGCU $-3^{\prime}$

$$
+33
$$

B
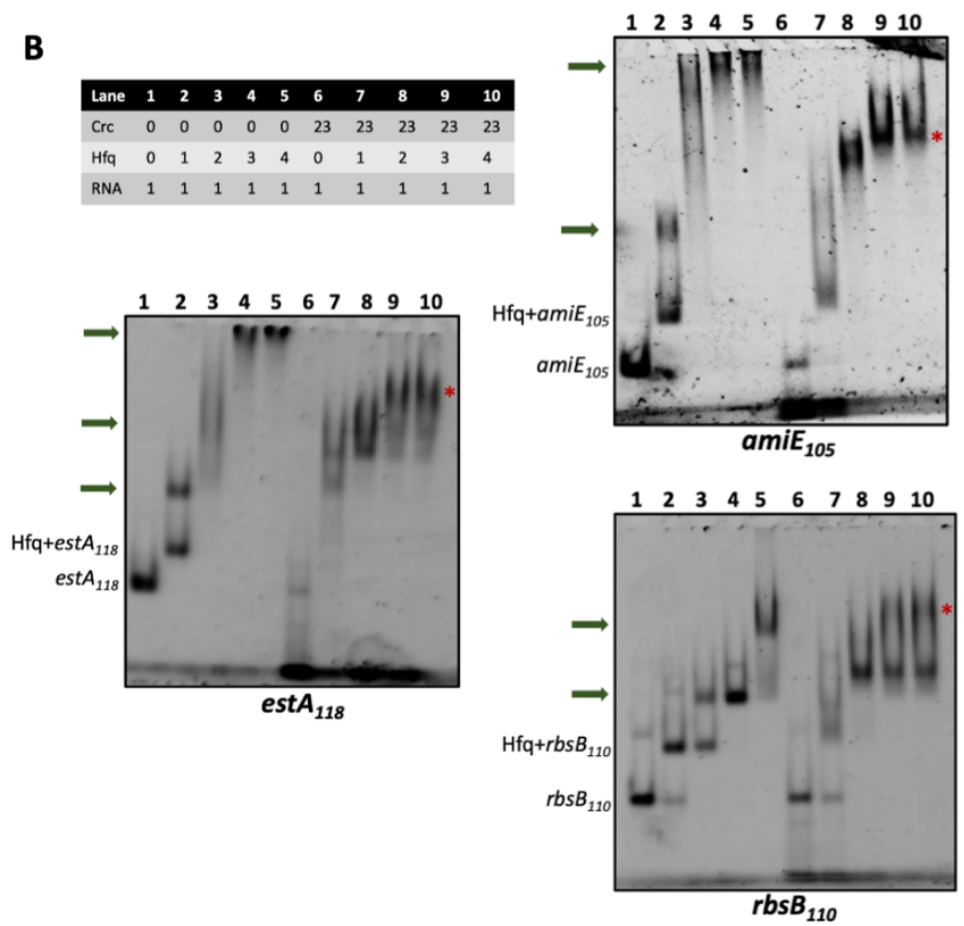

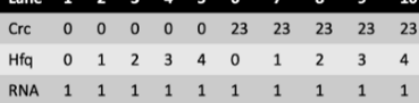

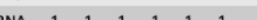

est $_{118}$

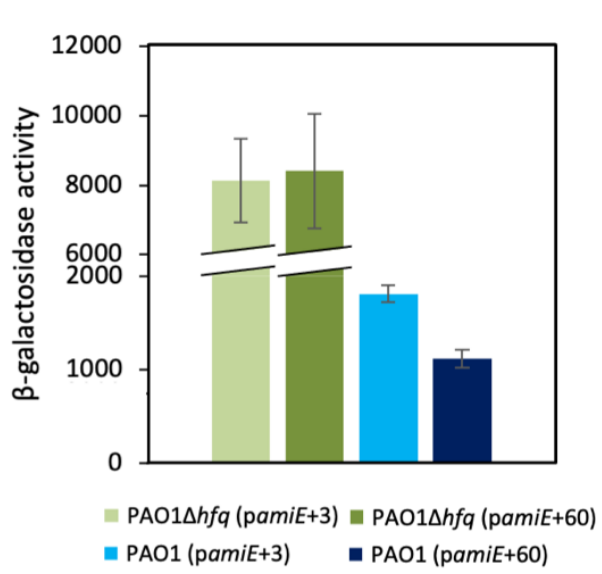

Supplementary Figure 1: Higher order $\mathrm{Hfq} / \mathrm{Crc}$ assemblies form on amiE $\mathrm{E}_{105}, \mathrm{rbs}_{110}$ and est $\mathrm{A}_{118} \mathrm{mRNA}$ segments. (A) Sequences of the $5^{\prime} U T R s$ and the proximal coding regions of amiE $E_{105}, r b s B_{110}$ and est $A_{118}$ mRNA fragments. ARN motifs are highlighted in yellow, Shine-Dalgarno sequences in blue rectangles and the AUG start codons are highlighted in blue. The amiE $_{\text {GARN }}$ segment used by Pei et al. (2019) is annotated as well as the shorter, secondary ARN $N_{X A R N}$ segment in the amiE coding region. (B) Electrophoretic mobility shift assays (EMSA) with amiE ${ }_{105}$, est $A_{118}$ and rbs $B_{110}$ transcripts in the presence of Hfq and Crc. Hfq and Crc can form higher order assemblies on all RNA targets tested. Hfq molecules can engage a single RNA molecule, both in the presence and absence of Crc. Top: The table shows relative stoichiometries in the samples (RNA is at $200 \mathrm{nM}$ ). The protein components were mixed first, after which the RNA fragments were added. Green arrows highlight Hfa-RNA oligomers, * highlights the highest order complexes for the stoichiometry range tested. (C-D) The downstream ARN cluster enhances translational repression of amiE in vivo. (C) Two translational amiE::lacZ reporter genes were constructed. The amiE+3::IacZ reporter gene contained a 29-nucleotide long amiE fragment encompassing the 5'UTR with the six ARN motifs (amiE $E_{6 A R N}$ ) and the AUG translation initiation codon fused to lacZ. The longer amiE+60::lacZ construct included additional 57 nucleotides downstream of the ATG start codon that encompass the second ARN-rich motif. (D) When compared with the expression in a P. aeruginosa strain lacking Hfq (PAO1 $\triangle$ hff), the translation of the amiE+60::IacZ gene in the PAO1 wt strain was repressed significantly stronger than that of the amiE+3::lacZ gene. These in vivo results support the structural data presented in Figure $4 A$ and $B$ in that the ARN-rich motif in the coding region of amiE can contribute to the formation of effective $\mathrm{Hfq}-\mathrm{Crc}$ repressive complexes in addition to the proximal amiE $E_{\text {GARN }}$ motif. 
bioRxiv preprint doi: https://doi.org/10.1101/2022.02.11.480102; this version posted February 12, 2022. The copyright holder for this

preprint (which was not certified by peer review) is the author/funder, who has granted bioRxiv a license to display the preprint in perpetuity. It is made available under aCC-BY 4.0 International license.
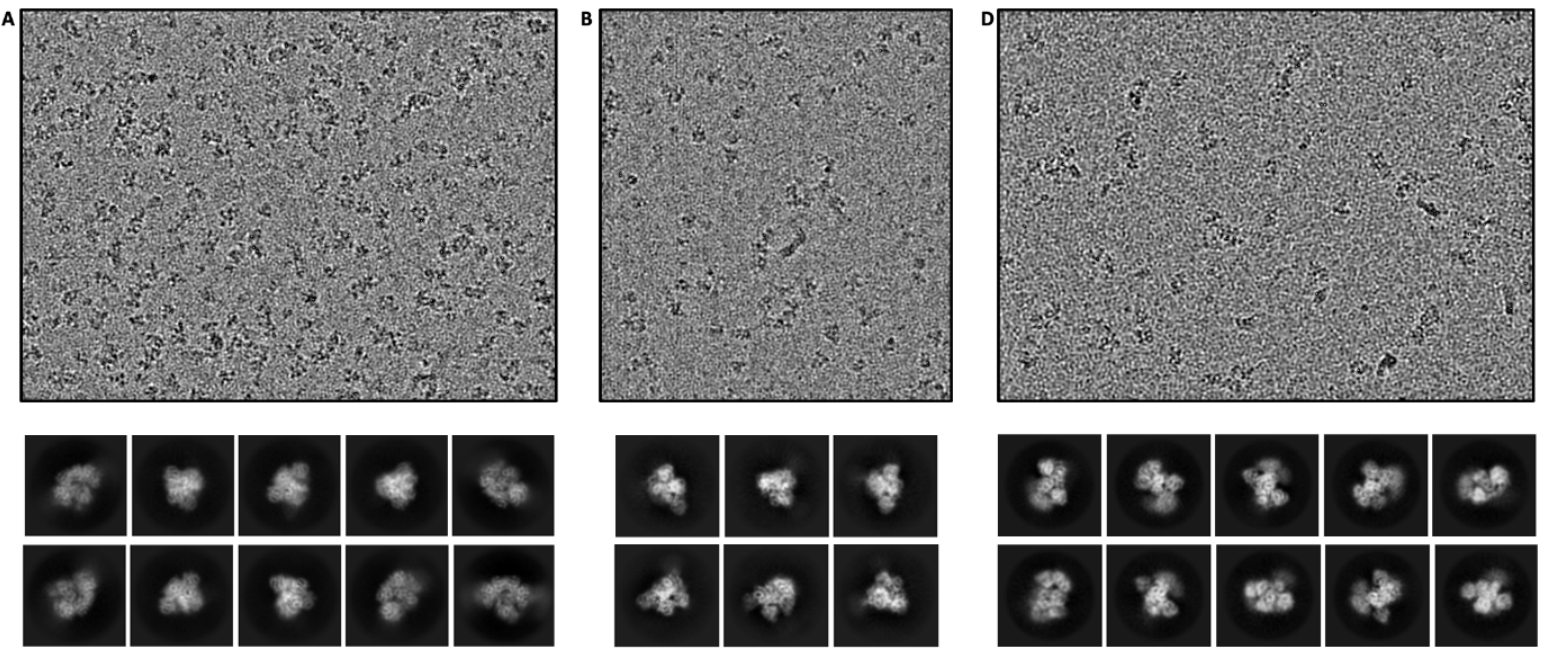

505

Supplementary Figure 2. Raw images and 2D class averages of the Hfq-Crc translation repression complexes formed on

506 $\operatorname{amiE}_{105}(A)$, est $A_{118}(B)$ and $r b s B_{110}(C)$.
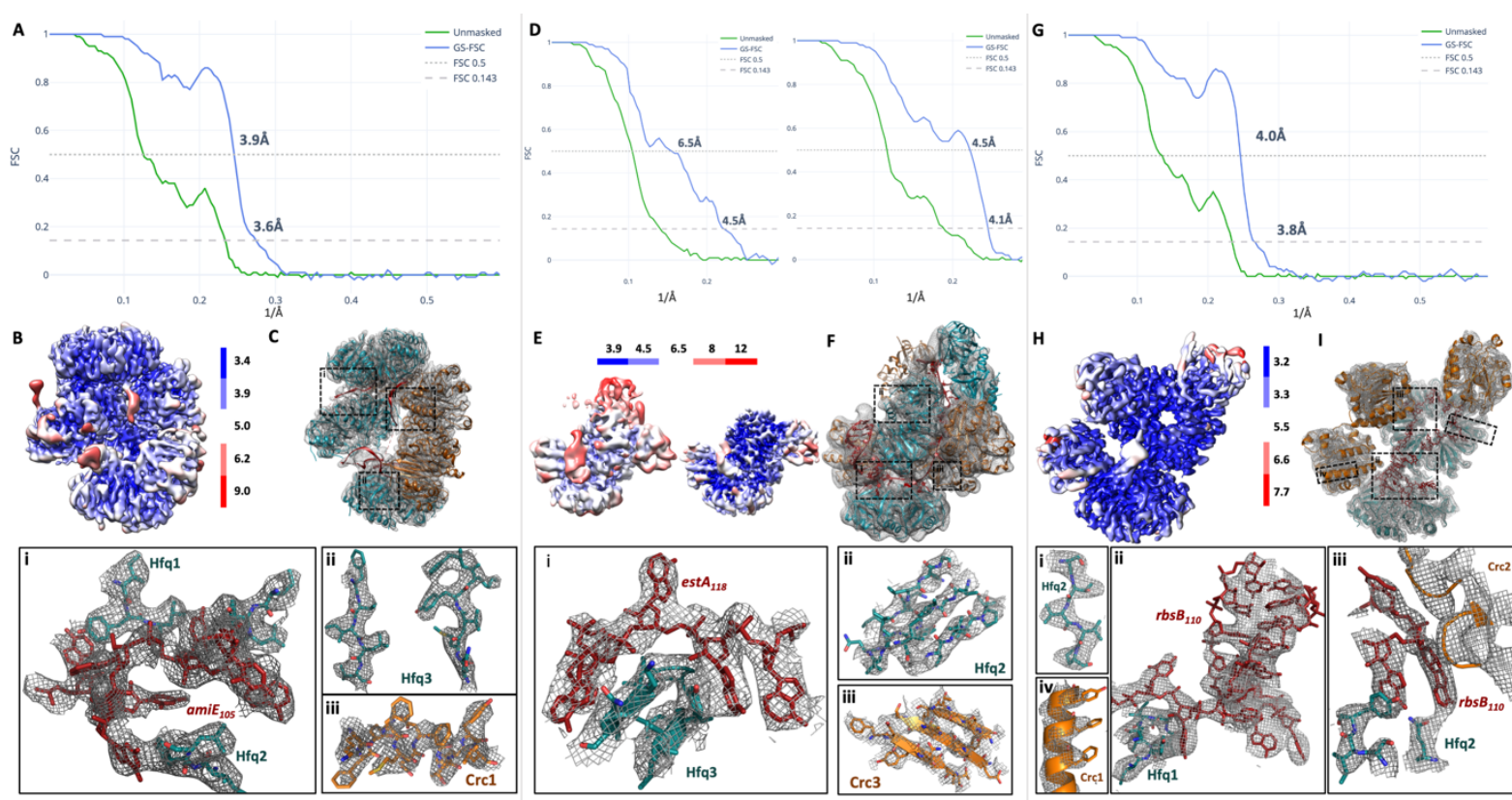

Supplementary Figure 3. Global and local resolution analyses of the $\mathrm{Hfq}$-Crc translation repression complexes formed on

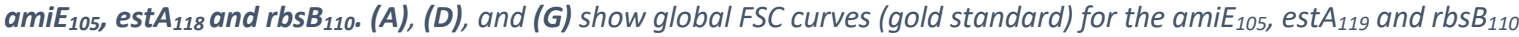
complexes, respectively. The left FSC curve in panel (D) corresponds to the global, consensus refinement, the right FSC curve corresponds to the focused refinement for the Hfq-estA119-Crc reconstruction. (B), (E) and (H) display local resolution estimates as measured by cryoSPARC at FSC 0.5.(C), (F) and (I) show the respective structures, coloured as before, docked into the experimental cryo-EM maps, with the insets showing close-up of selected areas for each. 
A

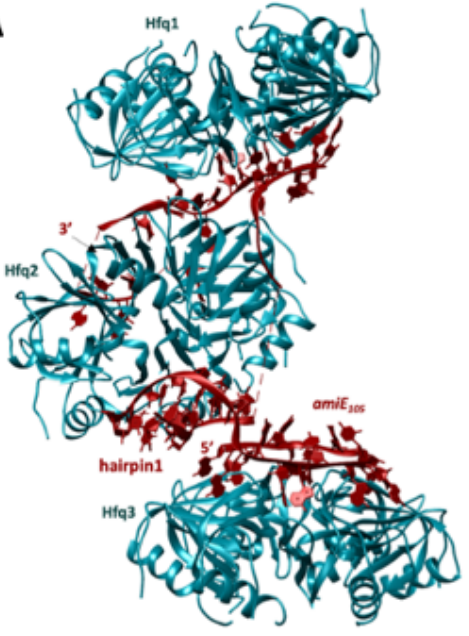

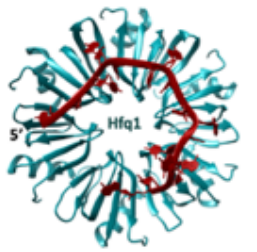
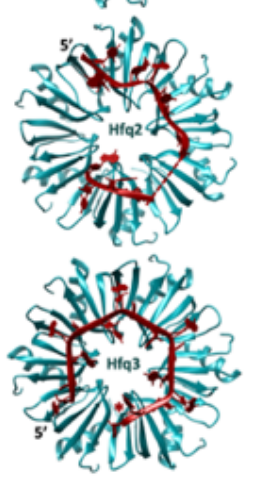
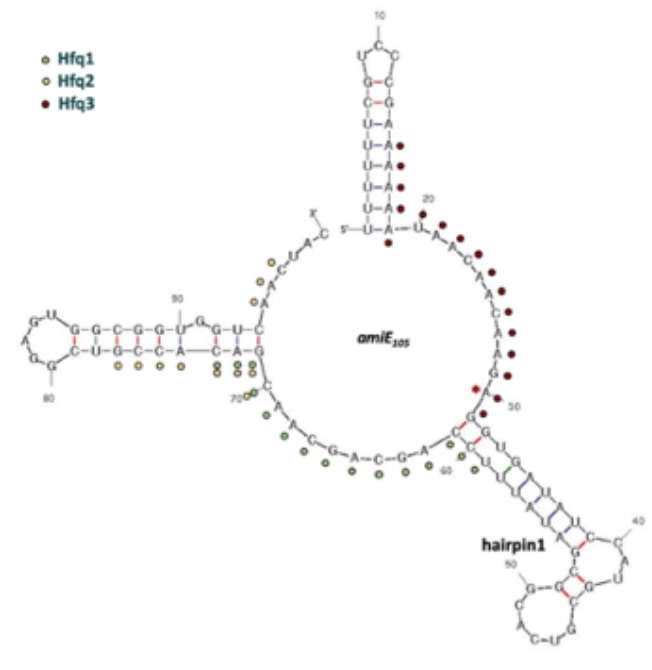

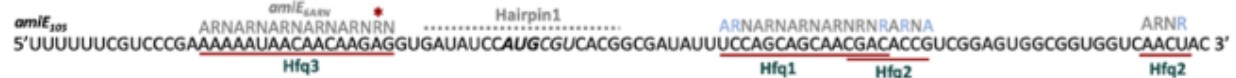

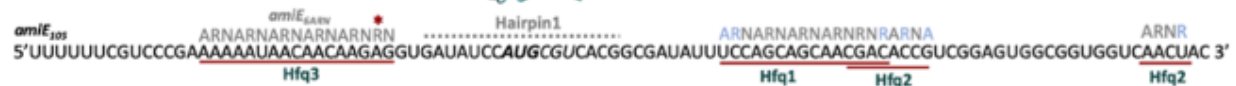

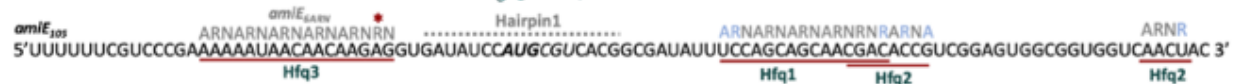

B
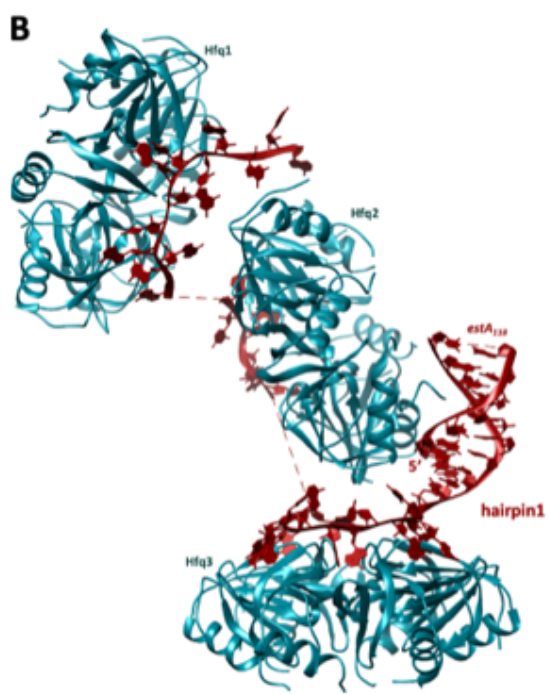
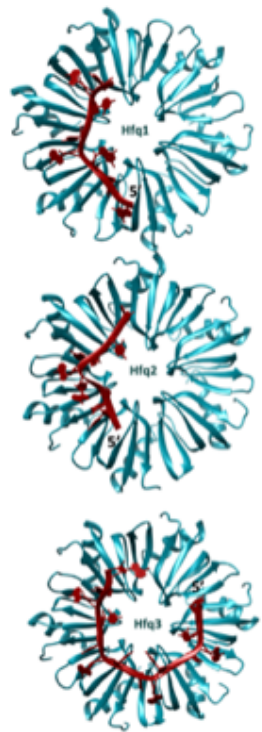

hairpin1 $1 . . . . . . . . . . . . .$. RNARNARNARNARN RNNARNR ARNABNA

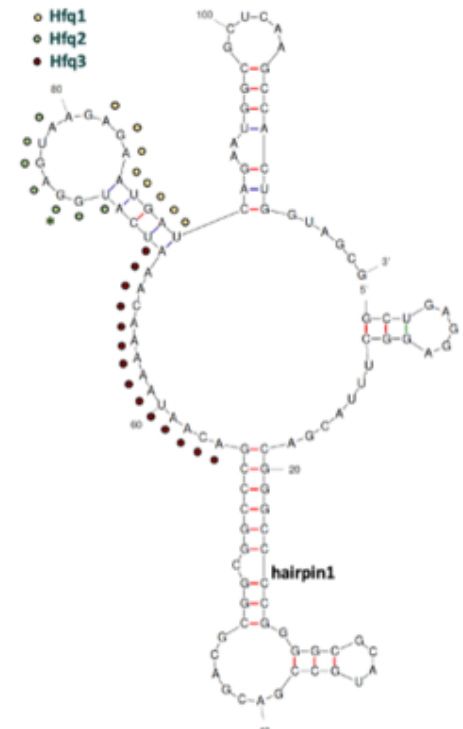

5'GCUGAGGAGGCUUUACGACGGGCCCCGGGGGCGCAUGCCGGACGACGCGGCGGCCCGACAAUAAAAACAAAUCAUGGAGUAAGAGAAUGAUCAGAAUGGCGCUCAAGCCACUGGUAGCG 3'

\section{C}
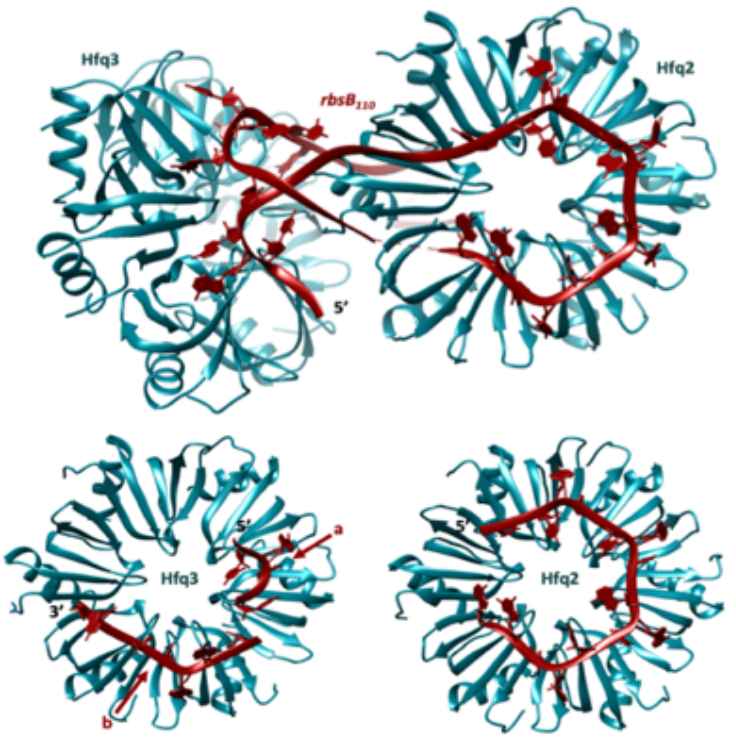

rbsis,

5'ABAB 110 RNGARARNARNARNN

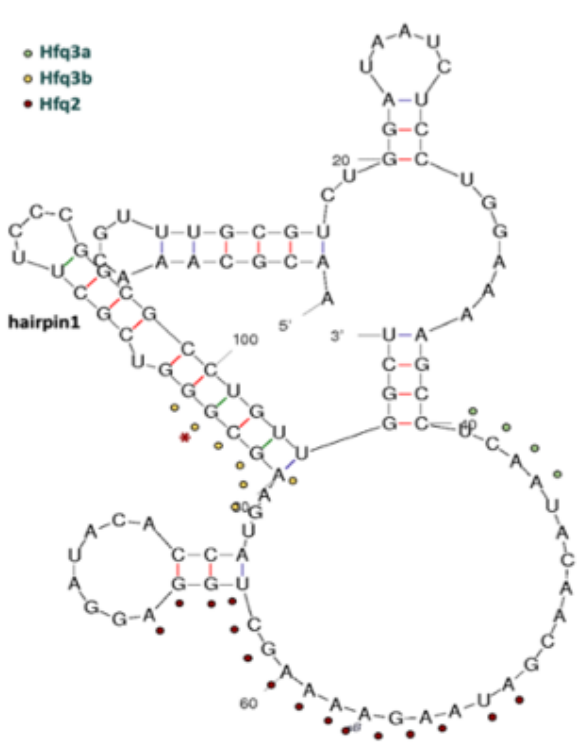

RNARNRN hairpin1 
bioRxiv preprint doi: https://doi.org/10.1101/2022.02.11.480102; this version posted February $12,2022$. The copyright holder for this

preprint (which was not certified by peer review) is the author/funder, who has granted bioRxiv a license to display the preprint in perpetuity. It is made available under aCC-BY 4.0 International license.

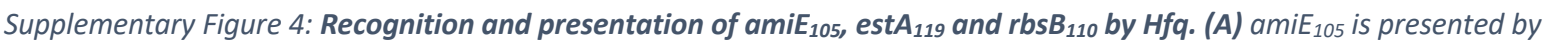
three $\mathrm{Hfq}$ hexamers and adopts complete or partial ARN motif engagement on each distal side. The proximal side of $\mathrm{Hfq} 2$ coordinates an amiE $E_{105}$ hairpin- loop structure (hairpin1). A second hairpin-loop forms at the 3' end of amiE $E_{105}$ on the $\mathrm{Hfq}_{2}$ distal side (hairpin2, not shown due to limited resolution). Right: annotated secondary structure prediction of amiE $E_{105}$

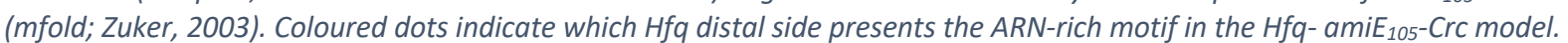
An annotated sequence is depicted at the bottom of the panel. Sequences that were mapped in the cryo-EM reconstruction are underlined in red and the Hfa distal sides they bind to are labelled in green. Occupied $A-, R$ - or $N$ - sites are annotated in grey above each modelled sequence. * refers to an A-site 'skipping'-violation, where the A-site on the Hfa distal site is not occupied by a base, i.e. skipped. Light blue letters refer to 'mismatch'-violations of the ARN-rule, where a pyrimidine base occupies an A-site or R-site pocket on the Hfq distal face. The ranges for hairpin1 and hairpin2 are arbitrary due to limited local resolution in the corresponding map regions. (B) est $A_{118}$ is presented by three Hfq hexamers and adopts partial ARN motif engagement on each Hfq distal side. The proximal side of Hfq2 coordinates an est $A_{118}$ hairpin- loop structure (hairpin 1). Right: annotated secondary structure prediction of est $A_{118}$ (mfold; Zuker, 2003). Coloured dots indicate which Hfq distal side presents the ARN-rich motif in the Hfq-Crc-estA $A_{118}$ model. An annotated sequence is depicted at the bottom of the panel. Sequences that were mapped in the cryo-EM reconstruction are underlined in red and the Hfa distal sides they bind to are labelled in green. Occupied $A$-, $R$ - or $N$ - sites are annotated in grey above each modelled sequence. ${ }^{*}$ refers to an $A$ site 'skipping'-violation, where the A-site on the Hfq distal site is not occupied by a base, i.e. skipped. Light blue letters refer to 'mismatch'-violations of the ARN-rule, where a pyrimidine base occupies an A-site or R-site pocket on the Hfa distal face. (C) $r b s B_{110}$ is presented by three Hfq hexamers (only the two that were well resolved in the cryo-EM maps are shown) and adopts partial ARN motif engagement on each $\mathrm{Hfq}$ distal side. The proximal side of $\mathrm{Hfq} 2$ coordinates a rbsB $\mathrm{B}_{110}$ hairpin- loop structure (hairpin1, in the back of the Hfa2 hexamer, not annotated in the figure. Right: annotated secondary structure prediction of $r b s B_{110}$ (mfold; Zuker, 2003). Coloured dots indicate which Hfq distal side presents the ARN-rich motif in the $H f q-r b s B_{110}-C r c$ model. An annotated sequence is depicted at the bottom of the panel. Sequences that were mapped in the cryo-EM reconstruction are underlined in red and the $\mathrm{Hfq}$ distal sides they bind to are labelled in green. Occupied A-, R-or $\mathrm{N}$ - sites are annotated in grey above each modelled sequence. * refers to an A-site 'skipping'-violation, where the A-site on the Hfq distal site is not occupied by a base, i.e. skipped. Light blue letters refer to 'mismatch'-violations of the ARN-rule, where a pyrimidine base occupies an A-site or R-site pocket on the Hfa distal face. The range for hairpin1 is arbitrary due to limited local resolution in the corresponding map region. 
bioRxiv preprint doi: https://doi.org/10.1101/2022.02.11.480102; this version posted February 12,2022 . The copyright holder for this

preprint (which was not certified by peer review) is the author/funder, who has granted bioRxiv a license to display the preprint in perpetuity. It is made available under aCC-BY 4.0 International license.

551 Table S1: Cryo-EM data collection and refinement statistics for the Hfq/Crc/RNA structures.

\begin{tabular}{|c|c|c|c|}
\hline Structure & Hfq- $a_{m i E_{105}-C r c}$ & Hfq- est $A_{118}-C r c$ & $\mathrm{Hfq}-\mathrm{rbs} \mathrm{B}_{110}-\mathrm{Crc}$ \\
\hline PDB code & $X X$ & $X X$ & $X X$ \\
\hline EMDB code & $x X$ & $x X$ & $x X$ \\
\hline \multicolumn{4}{|l|}{ Data collection } \\
\hline Microscope & $\begin{array}{l}\text { FEl Titan Krios } \\
\text { G2 }\end{array}$ & $\begin{array}{l}\text { FEl Titan Krios } \\
\text { G2 }\end{array}$ & $\begin{array}{l}\text { FEl Titan Krios } \\
\text { G2 }\end{array}$ \\
\hline Voltage (kV) & 300 & 300 & 300 \\
\hline Detector & Gatan K3 & Gatan K3 & Gatan K3 \\
\hline $\begin{array}{l}\text { Nominal } \\
\text { magnification }\end{array}$ & $105000 x$ & $105000 x$ & $105000 x$ \\
\hline Pixel size $(\AA)$ & 0.83 & 0.83 & 0.83 \\
\hline $\begin{array}{l}\text { Electron dose, } \\
\text { per frame }\left(\mathrm{e}^{-}\right. \\
\left./ \AA^{2}\right)\end{array}$ & 1.03 & 1.02 & 1.03 \\
\hline $\begin{array}{l}\text { Defocus range } \\
(\mu \mathrm{m})\end{array}$ & $-1.1 /-2.5$ & $-1.1 / 2.5$ & $-1.1 /-2.5$ \\
\hline Exposure (s) & 1.9 & 1.9 & 1.9 \\
\hline $\begin{array}{l}\text { Number of } \\
\text { micrographs }\end{array}$ & 14996 & 5532 & 6674 \\
\hline \multicolumn{4}{|l|}{ Reconstruction } \\
\hline Software & cryoSPARC 2.15 & cryoSPARC 2.15 & cryoSPARC 2.15 \\
\hline $\begin{array}{l}\text { Number of } \\
\text { particles used }\end{array}$ & 70572 & 61945 & 148739 \\
\hline $\begin{array}{l}\text { Final resolution, } \\
\text { FSC }_{0.143}(\AA)\end{array}$ & 3.6 & $4.4(4.1)$ & 3.8 \\
\hline $\begin{array}{l}\text { Map-sharpening } \\
\text { B factor }\left(\AA^{2}\right)\end{array}$ & -100 & -128 & -117 \\
\hline \multicolumn{4}{|l|}{ Model } \\
\hline $\begin{array}{l}\text { Composition } \\
\text { (Hfq:Crc:RNA) }\end{array}$ & $3: 4: 1$ & $3: 4: 1$ & $3: 3: 1$ \\
\hline $\begin{array}{l}\text { Non-hydrogen } \\
\text { atoms }\end{array}$ & 20109 & 19452 & 17218 \\
\hline Protein residues & 2269 & 2266 & 1979 \\
\hline $\begin{array}{l}\text { RNA } \\
\text { nucleotides }\end{array}$ & 83 & 53 & 52 \\
\hline $\begin{array}{l}\text { Molar Mass } \\
(\mathrm{kDa})\end{array}$ & 317 & 322 & 288 \\
\hline \multicolumn{4}{|l|}{ Refinement } \\
\hline Software & $\begin{array}{l}\text { Refmac5/Phenix/ } \\
\text { Isolde }\end{array}$ & $\begin{array}{l}\text { Refmac5/Phenix/ } \\
\text { Isolde }\end{array}$ & $\begin{array}{l}\text { Refmac5/Phenix/ } \\
\text { Isolde }\end{array}$ \\
\hline $\begin{array}{l}\text { Correlation } \\
\text { coefficient, } \\
\text { masked }\end{array}$ & 0.81 & 0.77 & 0.75 \\
\hline $\begin{array}{l}\mathrm{FSC}_{0.5} \text { (model- } \\
\text { map) }\end{array}$ & 3.9 & 7 & 3.6 \\
\hline Validation & & & \\
\hline $\begin{array}{l}\text { MolProbity } \\
\text { score }\end{array}$ & 1.67 & 2.1 & 1.50 \\
\hline
\end{tabular}


bioRxiv preprint doi: https://doi.org/10.1101/2022.02.11.480102; this version posted February 12,2022 . The copyright holder for this preprint (which was not certified by peer review) is the author/funder, who has granted bioRxiv a license to display the preprint in perpetuity. It is made available under aCC-BY 4.0 International license.

\begin{tabular}{|c|c|c|c|}
\hline $\begin{array}{l}\text { Clash score } \\
\text { Ramachandran }\end{array}$ & 5.06 & 8.5 & 2.80 \\
\hline $\begin{array}{l}\text { Favoured, } \\
\text { overall (\%) }\end{array}$ & 94.02 & 93.56 & 95.71 \\
\hline $\begin{array}{l}\text { Allowed, overall } \\
(\%)\end{array}$ & 5.75 & 6.08 & 3.67 \\
\hline $\begin{array}{l}\text { Outlier, overall } \\
(\%)\end{array}$ & 0.22 & 0.36 & 0.63 \\
\hline \multicolumn{4}{|l|}{$\begin{array}{l}\text { R.m.s. } \\
\text { deviations }\end{array}$} \\
\hline Bond length $(\AA)$ & 0.015 & 0.015 & 0.015 \\
\hline Bond angle $\left({ }^{\circ}\right)$ & 1.8 & 1.7 & 1.9 \\
\hline
\end{tabular}

552

553

554 


\section{MATERIALS AND METHODS}

\section{Purification of $P$. aeruginosa $\mathrm{Hfq}$ and Crc proteins}

The purification of $P$. aeruginosa $\mathrm{Hfq}$ and $\mathrm{Crc}$ is outlined in detail in Supplementary materials.

\section{Bacterial strains and plasmids}

The bacterial strains and plasmids used in this study are described in Supplementary materials.

\section{Preparation and purification of $a m i E_{105}, r b s B_{110}$ and est $A_{118} R N A$ fragments}

The RNA fragments $a m i E_{105}$ (comprises nt -45 to +60 of amiE mRNA with respect to the $A$ $(+1)$ of the start codon), $r b s B_{110}$ (comprises nt -75 to +33 of rbsB mRNA with respect to the $A$ $(+1)$ of the start codon plus two additional G-nucleotides at the $5^{\prime}$ end) and est $A_{118}$ (comprises nt -85 to +33 of estA mRNA with respect to the $A(+1)$ of the start codon) were prepared by in vitro transcription using T7 RNA polymerase. The DNA templates were amplified by PCR using the oligonucleotide pairs R185

(5' - TCTAGACGTAATACGACTCACTATAGGGCCTTTTTTCGTCCCGAAAAAATAACAAC-3') and Z172 (5'- GTAGTTGACCACCGCCACTC-3') (amiE $\left.{ }_{105}\right)$, P163 (5'-

AGATAATACGACTCACTATAGGAACGCAAACGTTTGCGTCTGGATAATCTCCT-3') and Q163 (5' AGCCAACAGGCGCCGGGAAGCGACCCGCTTCAT -3') (rbsB $\left.{ }_{110}\right)$ and T163 (5'AGATAATACGACTCACTATAGGCTGAGGAGGCTTTACGACGGGCCCCGGGG-3') and U163 (5'cgctaccagtggcttgagcgccattctgatCAT-3') (est $\left.A_{118}\right)$. The corresponding forward primers R185, P163 and T163, respectively, contained the T7 promoter sequence (underlined). After in vitro transcription with T7 RNA polymerase, the RNA fragments were gel purified using $8 \%$ polyacrylamide-8M urea gels.

\section{Electrophoretic mobility shift assays (EMSA)}

For the EMSAs, $4 \mu \mathrm{M}$ stocks of $\mathrm{Hfq}$ and $\mathrm{Crc}$ were prepared in binding-buffer $(20 \mathrm{mM}$ Tris- $\mathrm{HCl}$ $\mathrm{pH} 8.0,40 \mathrm{mM} \mathrm{NaCl}, 10 \mathrm{mM} \mathrm{KCl}, 1 \mathrm{mM} \mathrm{MgCl}_{2}$ ), and a $2 \mu \mathrm{M}$ stock of the RNAs was prepared in milliQ water (RNase free). The RNAs were annealed at $50^{\circ} \mathrm{C}$ for 3 minutes before the proteins were added. $4 \%$ poly-acrylamide (PAA) gels were used to study complex formation $(6.73 \mathrm{ml}$ acrylamide:bis-acrylamide, $5 \mathrm{ml} \mathrm{10x} \mathrm{TBE}, 37.7 \mathrm{ml}$ milliQ water, $500 \mu \mathrm{l} \mathrm{10 \%} \mathrm{APS}$ and $50 \mu \mathrm{l}$ TEMED). Hfq was titrated into a mixture of the RNAs ( $a m i E_{105}, r b s B_{110}$, and est $A_{118}$ ) at different ratios in the presence or absence of an excess of $\mathrm{Crc}$. The RNA concentration was kept constant at $200 \mathrm{nM}$. After 15 minutes of incubation at $37^{\circ} \mathrm{C}$, the samples were mixed with an equal volume of loading buffer $(50 \% \mathrm{v} / \mathrm{v}$ glycerol, $50 \% \mathrm{v} / \mathrm{v}$ binding buffer, $5 \mathrm{mM}$ $\mathrm{DTT})$, prior to loading them onto the gel. The gels were run at $4^{\circ} \mathrm{C}$ in $1 \mathrm{x}$ TBE running buffer and stained with SYBR gold. 


\section{Cryo-EM sample preparation}

For $\mathrm{Hfq}-\mathrm{Crc}$ assembly on amiE $E_{105}$, the RNA was annealed at $50^{\circ} \mathrm{C}$ for 3 minutes. $\mathrm{Hfq}$ and $\mathrm{CrC}$ were mixed at $1.6 \mu \mathrm{M}$ and $0.8-8.8 \mu \mathrm{M}$, respectively, prior to addition of amiE $105(800 \mathrm{nM}$ final concentration). After incubation on ice for 1 hour, the mixture was diluted 7-fold before loading onto grids. The $\mathrm{Hfq}-\mathrm{rbs} \mathrm{B}_{110} \mathrm{Crc}$ complex was prepared following a similar procedure. The $r b s B_{110}$ fragment was annealed at $50^{\circ} \mathrm{C}$ for 3 minutes. Hfq and $\mathrm{Crc}$ were mixed at $2.8 \mu \mathrm{M}$ and $9 \mu \mathrm{M}$, respectively, after which the RNA was added at $400 \mathrm{nM}$. After incubation at room temperature for 15 minutes and on ice for 1 hour, the mixture was diluted 4-fold prior to grid preparation. The $\mathrm{Hfq}$-est $\mathrm{A}_{118} \mathrm{Crc}$ complex was prepared following the same procedure as for the $\mathrm{rbs}_{110}$ assembly, but the final sample was not diluted prior to grid preparation.

\section{Grid preparation}

Graphene oxide (GO) grids were prepared from Quantifoil R1.2/1.3 grids. A 2mg/ml graphene oxide dispersion (Sigma Aldrich) was diluted 10-fold and spun down at $300 \mathrm{~g}$ for 30 seconds to remove large aggregates. The dispersion was then diluted 10-fold before applying $1 \mu$ to glow-discharged grids (0.29 mbar, 15 mA, 2 minutes, Pelco Easiglow glow discharger). After drying out, the grids were stored in a grid box for $24-48 \mathrm{~h}$ prior to usage. $3 \mu$ lof the sample was applied to the $\mathrm{GO}$ grids and after 30 s of incubation, excess sample was blotted away and frozen in liquid ethane (blot force -4 to 0 , blot time 3 seconds, Vitrobot markIV (Thermo Fischer)). The grids were screened on a 200 kV Talos Arctica (FEI) (Cryo-EM facility, Department of Biochemistry, University of Cambridge) and the movies were recorded on a 300 kV Titan Krios (Thermo Fischer) with either a Falcon III (Thermo Fischer) or K3 (Gatan) direct electron detector (MRC-LMB and BioCem facility, Department of Biochemistry, University of Cambridge).

\section{Single particle analysis, model building and refinement}

All datasets were pre-processed with Warp (Tegunov \& Cramer, 2019). Particle sets were cleaned up in CryoSparc (Punjani et al., 2017) via repetitive 2D classifications and heterogeneous refinements. Further extensive classifications in 2D were used to classify different assemblies observed on the grid for each of the mRNA targets. High resolution maps were generated for the highest order assemblies with non-uniform refinement in cryoSPARC (Punjani et al., 2019) and global- and per particle CTF refinements (Table S1). The Hfq-2CrcamiE $_{105}$ (147 000 particles, Figure 2A), 2Hfq-3Crc-amiE 105 (99 000 particles, Figure 2A) and $3 \mathrm{Hfq}-4 \mathrm{Crc}^{-a m i E_{105}}$ (70 000 particles) assemblies were refined to $3.2 \AA, 3.9 \AA$ and $3.6 \AA$ respectively. The $\mathrm{Hfq}$-Crc-est $A_{118}$ map was reconstructed $4.5 \AA$ after global refinements and

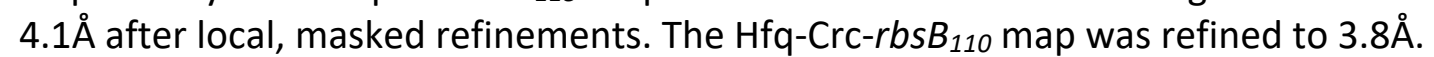

Crystal structures for $P$. aeruginosa $\mathrm{CrC}$ (PDB code 4JG3) and $\mathrm{Hfq}$ (PDB code 1U1T) were manually docked into the EM density map as rigid bodies in Chimera (Pettersen et al., 2004). The amiE $\mathrm{E}_{105}$, est $\mathrm{A}_{118}$ and $r b s B_{110}$ sequences were manually built into the density using Coot (Emsley et al., 2010). Refmac and Phenix real-space refinement with were used to iteratively refine the multi-subunit complexes, followed by manual corrections for Ramachandran and 
geometric outliers in Coot and ISOLDE (Table S1) (Emsley et al., 2010; Murshudov et al., 2011; Afonine et al., 2012; Croll, 2018). Model quality was evaluated with MolProbity (Williams et al., 2018).

\section{In vivo expression of the translational reporter genes}

The ability of $\mathrm{Hfq}, \mathrm{Crc}$ and $\mathrm{Crc}$ mutant proteins to repress the translation of the amiE+60::/acZ, $r b s B+13:: / a c Z$ and est $A+18:: l a c Z$ reporter genes was tested in the $P$. aeruginosa strains PAO1

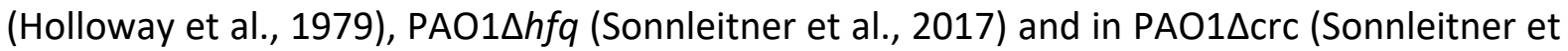
al., 2009) bearing plasmids pME4510 (vector control; Rist and Kertesz, 1998), pME4510 crc Flag (encodes the crc wt gene; Sonnleitner et al., 2018) or derivatives thereof encoding the Crc mutant proteins described in the text. The strains were grown to an $\mathrm{OD}_{600}$ of 2.0 in BSM medium (Sonnleitner et al., 2009) supplemented with $40 \mathrm{mM}$ succinate and $40 \mathrm{mM}$ acetamide (amiE+60::/acZ fusions) or only $40 \mathrm{mM}$ succinate ( $r b s B+13:: / a c Z$ and estA+18::/acZ fusions). The $\beta$-galactosidase activities were determined as described (Miller, 1972) using cells permeabilized with $5 \%$ toluene. The $\beta$-galactosidase units in the different experiments were derived from two independent experiments.

To account for possible differences in mRNA stability of the different estA+18::/acZ mRNAs (Figure $4 \mathrm{~J}$ ), the relative translational efficiencies were determined by normalizing the $\beta$ galactosidase values to the mRNA levels assessed by qRT-PCR. First, total RNA was purified by the hot phenol method (Leoni et al., 1996). The remaining DNA was digested with Turbo DNase (Thermo Fisher Scientific). $2 \mu \mathrm{g}$ of total RNA was used for CDNA synthesis with AMV reverse Transcriptase (Promega) together with 20 pmol of oligonucleotides $0135\left(5^{\prime}\right.$ TAGCGGCTGATGTTGAACTG-3', binds to lacZ) and M37 (5'-AGTCATGAATCACTCCGTGGTA-3'; binds to $16 \mathrm{~S}$ rRNA). $5 \mu$ of 20 -fold (lacZ) and 1000-fold (16S rRNA) diluted cDNA samples, respectively, were used as templates for qPCR with HOT FIREpol ${ }^{\circledR}$ EvaGreen ${ }^{\circledR}$ qPCR mix (Solis biodyne) and 5 pmol of oligonucleotides (/acZ: 0135/N135 (5'-ACTATCCCGACCGCCTTACT-3'); 16SrRNA: M37/L37 (5'- ATCGTAGTCCGGATCGCAGT-3')) in a $20 \mu$ l reaction. The qPCR reaction was performed in a Realplex 2 Mastercylcer (Eppendorf). The PCR efficiencies and relative expression ratios of the target genes (estA+18::lacZ and mutants thereof) in comparison to the reference gene (16S rRNA) were calculated as described in Pfaffl (2001). The relative translational efficiencies were determined by normalizing the $\beta$-galactosidase values to the mRNA levels of the corresponding fusion genes and setting the relative translational efficiency 


\section{Acknowledgements}

The work was supported by a Wellcome Trust Investigator award to BFL (200873/Z/16/Z). TD was supported by an AstraZeneca studentship. UB and ES were supported by the Austrian Science Fund (FWF) (P28711-B22). We express our gratitude to Flavia Bassani and Armin Resch for initial experiments and the provision of materials. We thank Kasia Bandyra, Ewelina Malecka-Grajek, Nancy Standart and Alexander Borodavka for helpful discussions and advice. All grids were prepared and cryo-EM data collected at the BIOCEM facility, Department of Biochemistry, University of Cambridge. We thank Dimitri Y. Chirgadze, Steven Hardwick, and Lee Cooper for assistance with data collection at the Cryo-EM Facility.

\section{References}

Abdou, L., Chou, H.T., Haas, D. and Lu, C.D. (2011) Promoter recognition and activation by the global response regulator CbrB in Pseudomonas aeruginosa. J Bacteriol, 193, 2784-2792.

Afonine, P.V., Grosse-Kunstleve, R.W., Echols, N., Headd, J.J., Moriarty, N.W., Mustyakimov, M., Terwilliger, T.C., Urzhumtsev, A., Zwart, P.H., and Adams, P.D. (2012). Towards automated crystallographic structure refinement with phenix.refine. Acta Crystallogr. D Biol. Crystallogr. 68, 352-367.

Ali Azam, T., Iwata, A., Nishimura, A., Ueda, S., \& Ishihama, A. (1999). Growth phasedependent variation in protein composition of the Escherichia coli nucleoid. Journal of bacteriology, 181(20), 6361-6370. https://doi.org/10.1128/JB.181.20.63616370.1999

Burnley, T., Palmer, C. M., \& Winn, M. (2017). Recent developments in the CCP-EM software suite. Acta crystallographica. Section D, Structural biology, 73(Pt 6), 469-477. https://doi.org/10.1107/S2059798317007859

Corona, F., Reales-Calderon, J.A., Gil, C. and Martinez, J.L. (2018) The development of a new parameter for tracking post-transcriptional regulation allows the detailed map of the Pseudomonas aeruginosa Crc regulon. Sci Rep, 8, 16793.

Croll, T.I. (2018). ISOLDE: a physically realistic environment for model building into lowresolution electron-density maps. Acta Cryst. D74

Dubey, A.K., Baker, C.S., Romeo, T. and Babitzke, P. (2005) RNA sequence and secondary structure participate in high-affinity CsrA-RNA interaction. $R N A, 11,1579-1587$.

Emsley, P., Lohkamp, B., Scott, W.G., and Cowtan, K. (2010). Features and development of Coot. Acta Crystallogr. D Biol. Crystallogr. 66, 486-501. 
Fernandez, L., Breidenstein, E.B., Taylor, P.K., Bains, M., de la Fuente-Nunez, C., Fang, Y., Foster, L.J., and Hancock, R.E. (2016). Interconnection of post-transcriptional regulation: the RNA-binding protein $\mathrm{Hfq}$ is a novel target of the Lon protease in Pseudomonas aeruginosa. Sci. Rep. 6, 26811.

Gebhardt, M.J., Kambara, T.K., Ramsey, K.M. and Dove, S.L. (2020) Widespread targeting of nascent transcripts by RsmA in Pseudomonas aeruginosa. Proc Natl Acad Sci U S A, 117, 10520-10529.

Goodman, A.L., Merighi, M., Hyodo, M., Ventre, I., Filloux, A. and Lory, S. (2009) Direct interaction between sensor kinase proteins mediates acute and chronic disease phenotypes in a bacterial pathogen. Genes Dev, 23, 249-259.

Herzel, L., Ottoz, D.S.M., Alpert, T., and Neugebauer, K.M. (2017). Splicing and transcription touch base: co-transcriptional spliceosome assembly and function. Nat. Rev. Mol. Cell. Biol. 18, 637-650.

Holmqvist, E., Wright, P.R., Li, L., Bischler, T., Barquist, L., Reinhardt, R., Backofen, R. and Vogel, J. (2016) Global RNA recognition patterns of post-transcriptional regulators Hfq and CsrA revealed by UV crosslinking in vivo. EMBO J, 35, 991-1011.

Huang, J., Sonnleitner, E., Ren, B., Xu, Y., and Haas, D. (2012). Catabolite repression control of pyocyanin biosynthesis at an intersection of primary and secondary metabolism in Pseudomonas aeruginosa. Appl. Environ. Microbiol. 78, 5016-5020.

Jakobi, A.J., Wilmanns, M. \& Sachse, C. 2017. Model-based local density sharpening of cryoEM maps. Elife. 6,1-26.

Kambara, T.K., Ramsey, K.M. and Dove, S.L. (2018) Pervasive targeting of nascent transcripts by Hfq. Cell Rep, 23, 1543-1552.

Krepl, M., Dendooven, T., Luisi, B. F., \& Sponer, J. (2021). MD simulations reveal the basis for dynamic assembly of Hfq-RNA complexes. J. Biol. Chem, 296, 100656. https://doi.org/10.1016/j.jbc.2021.100656

Leoni, L., Ciervo, A., Orsi, N. and Visca, P. (1996) Iron-regulated transcription of the $p v d A$ gene in Pseudomonas aeruginosa: effect of Fur and PvdS on promoter activity. $J$ Bacteriol.178, 2299-2313.

Lu, P., Wang, Y., Zhang, Y., Hu, Y., Thompson, K.M., and Chen, S. (2016). RpoS-dependent sRNA RgsA regulates Fis and AcpP in Pseudomonas aeruginosa. Mol. Microbiol. 102, 244-259.

Lynch, M., \& Marinov, G. K. (2015). The bioenergetic costs of a gene. Proceedings of the National Academy of Sciences of the United States of America, 112, 15690-15695. https://doi.org/10.1073/pnas. 1514974112 
Milojevic, T., Grishkovskaya, I., Sonnleitner, E., Djinovic-Carugo, K. and Bläsi, U. (2013) The Pseudomonas aeruginosa catabolite repression control protein Crc is devoid of RNA binding activity. PLoS One, 8, e64609.

Malecka, E.M. and Woodson, S.A. (2021) Stepwise sRNA targeting of structured bacterial mRNAs leads to abortive annealing. Mol. Cell 81, 1988-1999.

Malecka, E.M., Bassani, F., Dendooven, T., Sonnleitner, E., Rozner, M., Albanese, T.G., Resch, A., Luisi, B.F., Woodson, S. and Bläsi, U. (2021). Stabilization of Hfqmediated translational repression by the co-repressor Crc in Pseudomonas aeruginosa. Nucleic Acids Res. 49, 7075-7087.

Moreno, R., Hernandez-Arranz, S., La Rosa, R., Yuste, L., Madhushani, A., Shingler, V. and Rojo, F. (2015) The Crc and Hfq proteins of Pseudomonas putida cooperate in catabolite repression and formation of ribonucleic acid complexes with specific target motifs. Environ Microbiol, 17, 105-118.

Murshudov, G.N., Skubák, P., Lebedev, A.A., Pannu, N.S., Steiner, R.A., Nicholls, R.A., Vagin, A.A. (2011). REFMAC5 for the refinement of macromolecular crystal structures. Acta Crystallogr. D Biol. Crystallogr. 67, 355-367.

O'Toole, G.A., Gibbs, K.A., Hager, P.W., Phibbs, P.V.Jr., and Kolter, R. (2000). The global carbon metabolism regulator $\mathrm{Crc}$ is a component of a signal transduction pathway required for biofilm development by Pseudomonas aeruginosa. J. Bacteriol. 182, 425431.

Pei, X.Y., Dendooven, T., Sonnleitner, E., Chen, S., Bläsi, U. and Luisi, B.F. (2019) Architectural principles for Hfq/Crc-mediated regulation of gene expression. Elife, 8, e43158.

Pettersen, E.F., Goddard, T.D., Huang, C.C., Couch, G.S., Greenblatt, D.M., Meng, E.C., and Ferrin, T.E. (2004). UCSF Chimera - a visualization system for exploratory research and analysis. J. Comput. Chem. 25, 1605-1612.

Pfaffl, M.W. (2001) A new mathematical model for relative quantification in real-time RTPCR. Nucleic Acid Res. doi: 10.1093/nar/29.9.e45.

Punjani, A., Rubinstein, J.L., Fleet, D.J., and Brubaker, M.A. (2017). cryoSPARC: algorithms for rapid unsupervised cryo-EM structure determination. Nat. Methods 14, 290-296.

Punjani A., Zhang H., Fleet D.J. (2019) Non-uniform refinement: Adaptive regularization improves single particle cryo-EM reconstruction. bioRxiv, doi:10.1101/2019.12.15.877092.

Pusic, P., Tata, M., Wolfinger, M.T., Sonnleitner, E., Häussler, S. and Bläsi, U. (2016). Crossregulation by CrcZ RNA controls anoxic biofilm formation in Pseudomonas aeruginosa. Sci. Rep. 6, 39621.

Pusic, P., Sonnleitner, E., Krennmayr, B., Heitzinger, D.A., Wolfinger, M.T., Resch, A. and Bläsi, U. (2018) Harnessing Metabolic Regulation to Increase Hfq-Dependent Antibiotic Susceptibility in Pseudomonas aeruginosa. Front Microbiol. 9, 2709

Pusic, P., Sonnleitner, E., and Bläsi, U. (2021) Specific and global RNA regulators in Pseudomonas aeruginosa. Int. J. of Molec. Sci. doi: 10.3390/ijms22168632. 
Ramírez-Aportela, E., Vilas, J.L., Melero, R., Conesa, P. et al. 2020. Automatic local resolution-based sharpening of cryo-EM maps. Bioinformtics 36, 765-772.

Rodgers, M. L., \& Woodson, S. A. (2019). Transcription Increases the Cooperativity of Ribonucleoprotein Assembly. Cell 179, 1370-1381.e12. https://doi.org/10.1016/j.cell.2019.11.007

Rojo, F. (2010) Carbon catabolite repression in Pseudomonas: optimizing metabolic versatility and interactions with the environment. FEMS Microbiol Rev. 34, 658-684.

Romero, M., Silistre, H., Lovelock, L., Wright, V.J., Chan, K.G., Hong, K.W., Williams, P., Camara, M. and Heeb, S. (2018) Genome-wide mapping of the RNA targets of the Pseudomonas aeruginosa riboregulatory protein RsmN. Nucleic Acids Res. 46, 68236840.

Santiago-Frangos, A. and Woodson, S.A. (2018) Hfq chaperone brings speed dating to bacterial sRNA. Wiley Interdiscip. Rev. RNA. doi: 10.1002/wrna.1475.

Santiago-Frangos, A., Frohlich, K.S., Jeliazkov, J.R., Malecka, E.M., Marino, G., Gray, J.J., Luisi, B.F, Woodson, S.A. and Hardwick, S.W. (2019) Caulobacter crescentus Hfq structure reveals a conserved mechanism of RNA annealing regulation. Proc. Natl. Acad. Sci. U.S.A.. 116, 10978-10987.

Schubert, M., Lapouge, K., Duss, O., Oberstrass, F.C., Jelesarov, I., Haas, D. and Allain, F.H. (2007) Molecular basis of messenger RNA recognition by the specific bacterial repressing clamp RsmA/CsrA. Nat. Struct. Mol. Biol. 14, 807-813.

Sonnleitner, E., Hagens, S., Rosenau, F., Wilhelm, S., Habel, A., Jäger, K.E., and Bläsi, U. (2003) Reduced virulence of a $h f q$ mutant of Pseudomonas aeruginosa O1. Microb. Pathog. 35, 217-228.

Sonnleitner, E., Pusic, P., Wolfinger, M.T. and Bläsi, U. (2020) Distinctive Regulation of carbapenem susceptibility in Pseudomonas aeruginosa by Hfq. Front. Microbiol. 11, 1001.

Sonnleitner, E., Schuster, M., Sorger-Domenigg, T., Greenberg, E.P., and Bläsi, U. (2006). Hfq-dependent alterations of the transcriptome profile and effects on quorum sensing in Pseudomonas aeruginosa. Mol. Microbiol. 59, 1542-1558.

Sonnleitner, E. and Bläsi, U. (2014) Regulation of Hfq by the RNA CrcZ in Pseudomonas aeruginosa carbon catabolite repression. PLoS Genet, 10, e1004440.

Sonnleitner, E., Wulf, A., Campagne, S., Pei, X.Y., Wolfinger, M.T., Forlani, G., Prindl, K., Abdou, L., Resch, A., Allain, F.H. et al. (2018) Interplay between the catabolite repression control protein Crc, Hfq and RNA in Hfq-dependent translational regulation in Pseudomonas aeruginosa. Nucleic Acids Res, 46, 1470-1485.

Tegunov, D., Cramer, P. (2019). Real-time cryo-electron microscopy data preprocessing with Warp. Nat. Methods 16, 1146-1152. https://doi.org/10.1038/s41592-019-0580-y 
Valentini, M., Garcia-Maurino, S.M., Perez-Martinez, I., Santero, E., Canosa, I. and Lapouge, K. (2014) Hierarchical management of carbon sources is regulated similarly by the CbrA/B systems in Pseudomonas aeruginosa and Pseudomonas putida. Microbiology 160, 2243-2252.

Williams, C., Headd, J., Moriarty, N., Prisant, M., Videau, L., Deis, L., Verma, V., Keedy, D., Hintze, B., Chen, V., Jain, S., Lewis, S., Arendall, W., Snoeyink, J., Adams, P., Lovell, S., Richardson, J. and Richardson, D. (2017). MolProbity: More and better reference data for improved all-atom structure validation. Protein Science 27, 293-315.

Winsor G. L., Griffiths E. J., Lo R., Dhillon B. K., Shay J. A., Brinkman F. S. L. (2016). Enhanced annotations and features for comparing thousands of Pseudomonas genomes in the Pseudomonas genome database. Nucleic Acids Res. 44, 646-653. 10.1093/nar/gkv1227

Yang, N., Ding, S., Chen, F., Zhang, X., Xia, Y., Di, H., Cao, Q., Deng, X., Wu, M., Wong, C., Tian, X., Yang, C., Zhao, J. and Lan, L. (2015). The Crc protein participates in down-regulation of the lon gene to promote rhamnolipid production and quorum sensing in Pseudomonas aeruginosa. Mol.Microbiol. 96, 526-547.

Yu, A.M., Gasper, P.M., Cheng, L., Lai, L.B., Kaur, S., Gopalan, V., Chen, A.A. and Lucks, J.B. (2021) Computational reconstructing cotranscriptional RNA folding from experimental data reveals rearrangement of non-native folding intermediates. Mol. Cell 81, 870-883.

Zhang, K. (2016). Gctf: real-time CTF determination and correction. J. Struct. Biol. 193, 1-12.

Zhang, L., Chiang, W.C., Gao, Q., Givskov, M., Tolker-Nielsen, T., Yang, L., and Zhang, G. (2012). The catabolite repression control protein Crc plays a role in the development of antimicrobial-tolerant subpopulations in Pseudomonas aeruginosa biofilms. Microbiology 158, 3014-3019.

Zhang, Y.F., Han, K., Chandler, C.E., Tjaden, B., Ernst, R.K. and Lory, S. (2017) Probing the sRNA regulatory landscape of Pseudomonas aeruginosa: post-transcriptional control of determinants of pathogenicity and antibiotic susceptibility. Mol. Microbiol. 106, 919-937.

Zheng, S.Q, Palovcak, E., Armache, J.-P., Cheng, Y. and Agard, D.A. (2017). MotionCor2: anisotropic correction of beam-induced motion for improved cryo-electron microscopy. Nat. Methods 14, 331-332. 


\section{Supplementary materials}

895

896

897

898

899

900

901

902

903

904

905

906

907

908

909

910

911

912

913

914

915

916

917

918

919

920

921

922

923

924

925

926

927

928

929

930

931

932

933

934

935

936

937

938

939

940

\section{P. aeruginosa Hfa purification}

An Hfq-deficient Escherichia coli strain bearing plasmid pKEHfqPae encoding Pseudomonas aeruginosa $\mathrm{Hfq}$ (Sonnleitner et al., 2018) was grown in $50 \mathrm{ml}$ Lysogeny broth (LB) supplemented with $0.2 \% \mathrm{wt} / \mathrm{v}$ glucose, $15 \mu \mathrm{g} / \mathrm{ml}$ kanamycin, $50 \mu \mathrm{g} / \mathrm{ml}$ ampicillin at $37^{\circ} \mathrm{C}$ in an orbital shaker at $220 \mathrm{rpm}$ overnight. $5 \mathrm{ml}$ of the pre-culture was used to inoculate $4 \mathrm{~L}$ of LB (with the same supplements) at $37^{\circ} \mathrm{C}$, and the culture was grown in a shaker to an $\mathrm{OD}_{600 \mathrm{~nm}}$ of 0.6 , at which time expression of the $h f q$ gene was induced with 1 mM IPTG (isopropyl $\beta-D-1-$ thiogalactopyranoside). After continued growth at 4 hours, the cells were harvested by centrifugation at $5,000 \mathrm{~g}$ for 20 minutes at $4^{\circ} \mathrm{C}$, and the pellets were resuspended in $20 \mathrm{ml}$ lysis buffer ( $50 \mathrm{mM}$ Tris- $\mathrm{HCl} \mathrm{pH} 8,1.5 \mathrm{M} \mathrm{NaCl}, 250 \mathrm{mM} \mathrm{MgCl} 2,1 \mathrm{mM} \beta$-mercaptoethanol, $1 \mathrm{mM}$ EDTA, $1 \mathrm{mM}$ PMSF) and frozen in liquid nitrogen for storage at $-80^{\circ} \mathrm{C}$. The thawed cells were supplemented with $20 \mu \mathrm{g} / \mathrm{ml}$ DNase I and lysed using an Avestin Emulsiflex C5 homogeniser (5 passes, 1000 bar). The lysate was centrifuged at 35,000 g for 20 minutes at $4^{\circ} \mathrm{C}$, and the supernatant was collected and heated to $85^{\circ} \mathrm{C}$ in a water bath for 45 minutes. The precipitate was removed by a $20,000 \mathrm{~g}$ spin at $4^{\circ} \mathrm{C}$ for 15 minutes and $1 \mathrm{M}\left(\mathrm{NH}_{4}\right)_{2} \mathrm{SO}_{4}$ was gradually added to the supernatant. The precipitate was pelleted at $20,000 \mathrm{~g}$ for 15 minutes $\left(4^{\circ} \mathrm{C}\right)$, then the supernatant was filtered through a $0.42 \mu \mathrm{m}$ Sartorius Minisart syringe filter. The sample was applied to a $5 \mathrm{ml} \mathrm{HiTrap} \mathrm{Butyl} \mathrm{HP}$ column (GE Lifesciences) equilibrated in buffer A (50 mM Tris- $\mathrm{HCl} \mathrm{pH} \mathrm{8,} 1.5 \mathrm{M} \mathrm{NaCl}, 1.5 \mathrm{M}\left(\mathrm{NH}_{4}\right)_{2} \mathrm{SO}_{4}, 0.5 \mathrm{mM} \beta$-mercaptoethanol, $0.5 \mathrm{mM}$ EDTA and $0.1 \mathrm{mM}$ PMSF). After loading, 10 column volumes of buffer $A$ were used to remove contaminants, and a $0-100 \%$ linear gradient of buffer $B(50 \mathrm{mM}$ Tris- $\mathrm{HCl}$ pH 8.0, $200 \mathrm{mM} \mathrm{NaCl}$, $0.5 \mathrm{mM} \beta$-mercaptoethanol, $0.5 \mathrm{mM}$ EDTA and $0.1 \mathrm{mM}$ PMSF (phenylmethysulfonyl fluoride)) was used to elute Hfq. The eluted protein was diluted two-fold in buffer Hep-A (50 mM Tris$\mathrm{HCl} \mathrm{pH} \mathrm{8.0,} 100 \mathrm{mM} \mathrm{NaCl}, 0.5 \mathrm{mM} \beta$-mercaptoethanol, $0.5 \mathrm{mM}$ EDTA and 0.1 mM PMSF) and loaded on a $5 \mathrm{ml}$ HiTrap Heparin column (GE Lifesciences) equilibrated with buffer Hep-A. 10 column volumes of Buffer Hep-A where then used to wash of any remaining contaminants. $\mathrm{Hfq}$ was eluted with a linear 0-60\% gradient of buffer Hep-B (50 mM Tris- $\mathrm{HCl}$ pH 8.0, $2 \mathrm{M}$ $\mathrm{NaCl})$. Next, the peak fractions were pooled and concentrated in an Amicon Ultra centrifugal filter unit (10 kDa cutoff) to a final volume of $500 \mu$ l. The sample was then loaded on a Superdex 200 Increase 10/300 GL (GE Lifesciences) equilibrated with Buffer SEC-A (50mM Tris- $\mathrm{HCl} \mathrm{pH} \mathrm{7.5,} 200 \mathrm{mM} \mathrm{NaCl}, 10 \% \mathrm{v} / \mathrm{v}$ glycerol). The peak fractions were flash frozen and stored at $-80^{\circ} \mathrm{C}$. An SDS-PAGE denaturing gel was run with the peak fractions to assess purity.

\section{P. aeruginosa Crc purification}

Plasmid pETM14lic-6His-Crc was transformed into competent E. coli BL21DE3 cells by standard heat shock transformation, and the cells were plated on LB-agar plates supplemented with $50 \mu \mathrm{g} / \mathrm{ml}$ kanamycin. A pre-culture of the cells was grown overnight in 50 $\mathrm{ml} \mathrm{LB}$ medium supplemented with $50 \mu \mathrm{g} / \mathrm{ml}$ kanamycin. $4 \times 800 \mathrm{ml}$ of LB, supplemented with $50 \mu \mathrm{g} / \mathrm{ml}$ kanamycin, $0.2 \%$ glucose and $2 \mathrm{mM} \mathrm{Mg}_{2} \mathrm{SO}_{4}$, were inoculated with $4 \mathrm{ml}$ of the preculture. $3 \mathrm{mM}$ of IPTG (final concentration) was used to induce expression of the crc gene at an $\mathrm{OD}_{600 \mathrm{~nm}}$ of 0.6. After 3 hours, the cells were harvested by centrifugation at 5,000 $\mathrm{g}$ for 20 minutes. The pellet was resuspended in $50 \mathrm{ml} \mathrm{Ni-A}$ buffer $(50 \mathrm{mM}$ Tris- $\mathrm{HCl}$ pH 8.0, $300 \mathrm{mM}$ $\mathrm{NaCl}, 10 \mathrm{mM}$ imidazole, $1 \mathrm{mM} \beta$-mercaptoethanol, $0.1 \mathrm{mM} \mathrm{PMSF}$ ), frozen in liquid nitrogen 
and stored at $-80^{\circ} \mathrm{C}$. The thawed cells were supplemented with $20 \mu \mathrm{g} / \mathrm{ml} \mathrm{DNase} \mathrm{I} \mathrm{and} 20 \mu \mathrm{g} / \mathrm{ml}$ RNase $A$ and lysed using an Avestin Emulsiflex $\mathrm{C} 5$ homogeniser ( 5 passes, 1000 bar). The lysate was centrifuged for 30 minutes at $30,000 \mathrm{~g}\left(4^{\circ} \mathrm{C}\right)$, and the supernatant was loaded on a $5 \mathrm{ml}$ $\mathrm{HiTrap}$ chelating column charged with $\mathrm{NiSO}_{4}$ and equilibrated in buffer $\mathrm{Ni}-\mathrm{A}$. The column was washed with 10 column volumes of buffer Ni-W $\left(50 \mathrm{mM} \mathrm{NaH}{ }_{2} \mathrm{PO}_{4}, 300 \mathrm{mM} \mathrm{NaCl}, 20 \mathrm{mM}\right.$ imidazole, $\mathrm{pH}$ 8.0) and eluted with a linear $0-60 \%$ gradient of buffer $\mathrm{Ni}-\mathrm{B}$ ( $50 \mathrm{mM} \mathrm{NaH} \mathrm{PO}_{4}$, $300 \mathrm{mM} \mathrm{NaCl}, 500 \mathrm{mM}$ imidazole, $\mathrm{pH}$ 8.0). The peak fractions were pooled and dialyzed in 50 $\mathrm{mM}$ Hepes $\mathrm{pH} 8,150 \mathrm{mM} \mathrm{NaCl}, 1 \mathrm{mM} \beta$-mercaptoethanol and the concentration was measured with a NanoDrop spectrophotometer (Thermo Fisher). For each mg of protein, 20 $\mu \mathrm{g}$ PreScission Protease (Sigma Aldrich) was added to cleave the His-tag. After 2 hours of incubation at $4^{\circ} \mathrm{C}$, the sample was applied to a nickel column to remove the cleaved His-tags and PreScission Protease, and the flow through was concentrated with an Amicon Ultra centrifugal filter (5 kDa cutoff). The sample was loaded on a Superdex 200 Increase 10/300 GL (GE Lifesciences) equilibrated with Buffer SEC-A (50 mM Hepes pH 8.0, $150 \mathrm{mM} \mathrm{NaCl}, 1$ $\mathrm{mM}$ TCEP (tris(2-carboxyethyl) phosphine) and $10 \% \mathrm{v} / \mathrm{v}$ glycerol). The peak fractions were flash frozen and stored at $-80^{\circ} \mathrm{C}$. An SDS-PAGE denaturing gel was run with the peak fractions to assess purity.

\section{Bacterial strains / plasmids used in this study and construction of lacZ-reporter genes}

To construct translational gene fusions between amiE and lacZ, DNA fragments containing nucleotides from -242 to $+3(a m i E+3)$ and to $+60(a m i E+60)$, respectively, with regard to the $A(+1)$ of the start codon of $a m i E$, were amplified by $P C R$ using the oligonucleotides A1 (5'-TTTTTTGAATTCGGCTGCATGCTATCTCAGGCGC-3') and either F173 (amiE+3; 5'-TTTTTTCTGCAGGTAGTTGACCACCGCCACTC-3') or G173 (amiE+60; 5'TTTTTTCTGCAGCATGGATATCACCTCTTGTTG-3') and chromosomal DNA of strain PAO1 as template. The PCR fragments were cleaved with EcoRI and Pstl and then ligated into the corresponding sites of plasmid pME6015 (Schnider-Keel et al., 2000), generating plasmids pamiE+3::lacZ and pamiE+60::lacZ, respectively.Plasmid prbsB+13::lacZ was constructed as described in Kambara et al. (2018). A DNA fragment containing nucleotides from -372 to +13 with regard to the $A(+1)$ of the start codon of $r b s B$, was amplified by PCR using the oligonucleotide pair T191 (5'- ATATGAATTCGTCCAGCCTGGAGGTCTACAAG-3') and U191 (5'ATATCTGCAGCGACCCGCTTCATGGTG-3') and chromosomal DNA of strain PAO1 as template. The PCR fragments were cleaved with EcoRI and Pst and then ligated into the corresponding sites of plasmid pME6015 (Schnider-Keel et al., 2000), generating plasmid prbsB+13::lacZ.

The construction of pestA+18::lacZ has been described by Sonnleitner \& Bläsi (2014), wherein it was termed pTLestA. Plasmid pest $A+18:$ :lacZ contains a DNA fragment of est $A$ spanning nucleotides -580 to +18 with regard to the $A(+1)$ of the start codon of estA.

Plasmid pTLestA- $\triangle C A$ (herein termed pestA+13 $\triangle C A:$ :lacZ), wherein a part of the $\mathrm{Hfq} 3$ binding site (AAAACAA) in estA was mutated to TCAGTAGC ( $\mathrm{Hfq} 3_{\text {mut }}$ in Figure 4 ) has been described in Sonnleitner et al. (2012)).

Plasmid pestA+18- $\Delta \mathrm{hp1}$ ::/acZ was constructed employing overlapping PCR. The PCR fragments were amplified with primer pairs Q67 (5'-TTTTTGAATTCGAGCAGCCTGGCACGC3')/G191 (5'-TCGTAAAGCCTCCTCAG-3') and H191 (5'- 

TTTTGGATCCGAGCGCCATTCTGATCAT-3') and pestA+18::/acZ as template. The PCR fragments were combined and used as a template for a second overlapping PCR with primers Q67 and R67. The resulting PCR fragment, comprising fragment of est $A$ from nucleotide -580 to +18 with a deletion of 37 nucleotides from nucleotides -66 to -30 with regard to the $A(+1)$ of the start codon of estA was digested with $E c o \mathrm{RI}$ and $\mathrm{BamHI}$ and ligated into the corresponding sites of pME6015.

Construction of plasmids encoding Crc variant proteins

Derivatives of plasmid pME4510crCFlag (Sonnleitner et al., 2018) were constructed by site directed mutagenesis using plasmid pME4510 $\mathrm{crc}_{\mathrm{Flag}}$ as template and the mutagenic oligonucleotide pairs E191 (5'-GAGCAAGCAGCGTGCCGCGGCCGCCGAATACATCTACTGC-3')/ F191 (5'- GCAGTAGATGTATTCGGCGGCCGCGGCACGCTGCTTGCTC-3') (CrC R138A,K139A,R140A,R141A), N191 (5'-CGATCGTTACGGGGAATTCCTGCAAGCCGACTTCGACAAGG-3')/ $0191 \quad\left(5^{\prime}-\right.$ 1004 CCTTGTCGAAGTCGGCTTGCAGGAATTCCCCGTAACGATCG-3') (CrC $\left.{ }^{\prime}\right)$ R90E,Y91F), L191 (5'respectively. The parental plasmid templates were digested with Dpnl and the mutated nicked circular strands were transformed into $E$. coli XL1-Blue, generating plasmid pME4510crC(R138A,K139A,R140A,R141A)Flag, PME4510CrC(R90E,Y91F)Flag and pME4510CrC(E61R,E86R)Flag. The construction of plasmids pME4510crC(E193R)Flag, pME4510crC(R230E)Flag, pME4510crC(E193R,R230E)Flag, pME4510crC(E193A,R230E)Flag, PME4510CrC(R229A,R230E)Flag and pME4510 $\mathrm{crC}_{(\mathrm{R} 140 \mathrm{E}) \mathrm{Flag}}$ as described in Pei et al. (2019). 